\title{
Modeling Molten Salt Spreading and Heat Transfer using MELTSPREAD - An Uncertainty Analysis
}

Chemical and Fuel Cycle Technologies Division, Argonne National Laboratory 


\begin{abstract}
About Argonne National Laboratory
Argonne is a U.S. Department of Energy laboratory managed by UChicago Argonne, LLC under contract DE-AC02-06CH11357. The Laboratory's main facility is outside Chicago, at 9700 South Cass Avenue, Argonne, Illinois 60439. For information about Argonne and its pioneering science and technology programs, see www.anl.gov.
\end{abstract}

\title{
DOCUMENT AVAILABILITY \\ Online Access: U.S. Department of Energy (DOE) reports produced after 1991 and a growing number of pre-1991 documents are available free at OSTI.GOV (http://www.osti.gov/), a service of the US Dept. of Energy's Office of Scientific and Technical Information.
}

\author{
Reports not in digital format may be purchased by the public from the \\ National Technical Information Service (NTIS): \\ U.S. Department of Commerce \\ National Technical Information Service \\ 5301 Shawnee Rd \\ Alexandria, VA 22312 \\ www.ntis.gov \\ Phone: (800) 553-NTIS (6847) or (703) 605-6000 \\ Fax: (703) 605-6900 \\ Email: orders@ntis.gov
}

Reports not in digital format are available to DOE and DOE contractors from the Office of Scientific and Technical Information (OSTI):

U.S. Department of Energy

Office of Scientific and Technical Information

P.O. Box 62

Oak Ridge, TN 37831-0062

www.osti.gov

Phone: (865) 576-8401

Fax: (865) 576-5728

Email: reports@osti.gov

\section{Disclaimer}

This report was prepared as an account of work sponsored by an agency of the United States Government. Neither the United States Government nor any agency thereof, nor UChicago Argonne, LLC, nor any of their employees or officers, makes any warranty, express or implied, or assumes any legal liability or responsibility for the accuracy, completeness, or usefulness of any information, apparatus, product, or process disclosed, or represents that its use would not infringe privately owned rights. Reference herein to any specific commercial product, process, or service by trade name, trademark, manufacturer, or otherwise, does not necessarily constitute or imply its endorsement, recommendation, or favoring by the United States Government or any agency thereof. The views and opinions of document authors expressed herein do not necessarily state or reflect those of the United States Government or any agency thereof, Argonne National Laboratory, or UChicago Argonne, LLC. 


\section{Modeling Molten Salt Spreading and Heat Transfer using MELTSPREAD - An Uncertainty Analysis}

Prepared by

Sara Thomas and Josh Jackson

Chemical and Fuel Cycle Technologies Division, Argonne National Laboratory

Mitchell Farmer

Nuclear Science and Engineering Division, Argonne National Laboratory

September 30, 2021 


\section{Acknowledgements}

This report was produced under the auspices of the US DOE Fuel Cycle R\&D program Advanced Reactors Regulatory Development Campaign. Issuance of this report meets milestone M3RD$21 \mathrm{AN} 06010512$.

This work was conducted at Argonne National Laboratory and supported by the U.S. Department of Energy, Office of Nuclear Energy, under Contract DE-AC02-06CH11357. 


\section{Table of Contents}

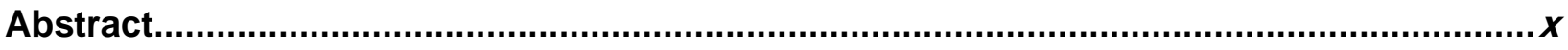

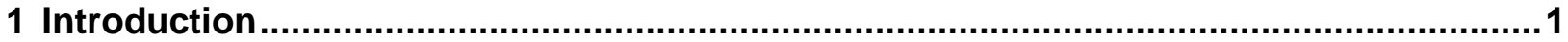

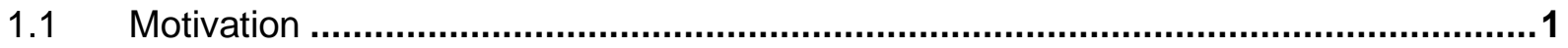

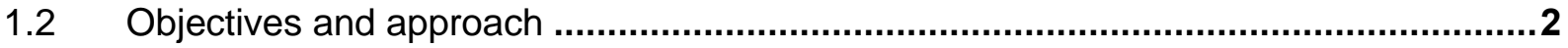

2 Thermophysical properties of FLiNaK used in MELTSPREAD .....................................

3 MELTSPREAD model input and description .............................................................4

3.1 Model description and spill conditions of the base case scenario ................................4

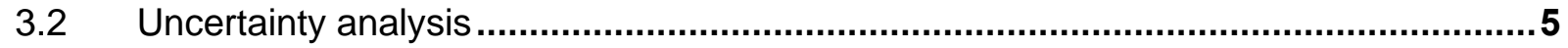

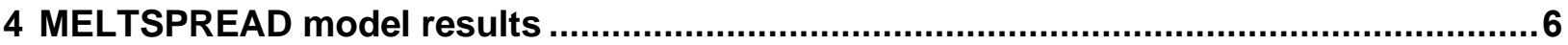

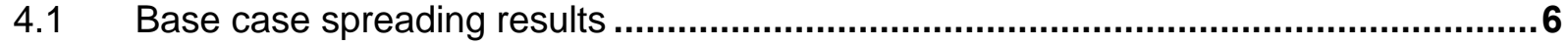

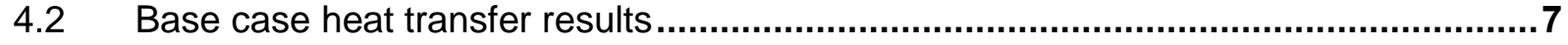

4.3 Effect of substrate thickness on heat transfer and spreading ..................................10

4.4 Effect of decay heat on heat transfer and spreading ..............................................12

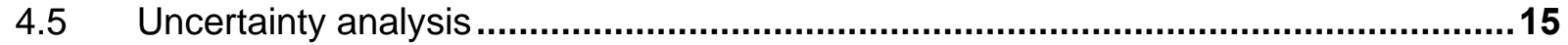

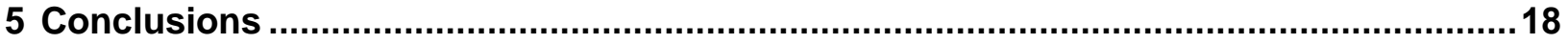

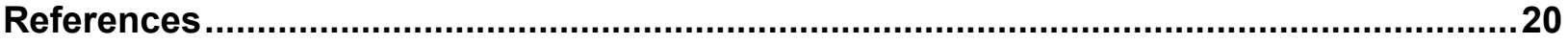

Appendix A: Estimating spreading area limit due to heat transfer and surface tension...22 


\section{Figures}

1. Schematic of the radial spreading of molten salt poured onto a flat substrate that was modeled using MELTSPREAD...

2. The extent of spreading of molten FLiNaK on a flat stainless steel substrate for the base case condition plotted as the leading edge radius as a function of time. 7

3. Integrated heat transfer rate up (to atmosphere) and down (to $1 / 16$ in. thick stainless steel substrate) predicted by MELTSPREAD for the base case pour scenario. 8

4. Integrated energy transfer up (to atmosphere) and down (to $1 / 16$ in. thick stainless steel substrate) predicted by MELTSPREAD for the base case pour scenario. 8

5. The surface temperatures of the top and underside of the $1 / 16$ in. thick stainless steel substrate at the location of melt impact $\left(r_{0}\right)$ predicted by MELTSPREAD for the base case pour scenario.

6. Integrated heat transfer rate up (to atmosphere) and down (to $1 / 4$ in. thick stainless steel substrate) predicted by MELTSPREAD for the base case pour conditions.

7. Integrated energy transfer up (to the atmosphere) and down (to the $1 / 4$ in. thick stainless steel substrate) predicted by MELTSPREAD for the base case pour conditions.

8. The surface temperatures of the top and underside of the $1 / 4$ in. thick stainless steel substrate at the impact location ( $\left.r_{0}\right)$ predicted by MELTSPREAD for the base case pour conditions.

9. Integrated heat transfer rate up (to atmosphere) and down (to $1 / 16$ in. thick stainless steel substrate) predicted by MELTSPREAD for the base case pour scenario with $25 \mathrm{MW} \mathrm{m}^{-3}$ of decay heat included.

10. The surface temperatures of the top and underside of the $1 / 16$ in. thick stainless steel substrate at the location of melt impact $\left(r_{0}\right)$ predicted by MELTSPREAD for the base case pour scenario with $25 \mathrm{MW} \mathrm{m}^{-3}$ of decay heat included.

11. Integrated energy transfer up (to atmosphere) and down (to $1 / 16$ in. thick stainless steel substrate) predicted by MELTSPREAD for the base case pour scenario with $25 \mathrm{MW} \mathrm{m}^{-3}$ of decay heat included.

12. Integrated heat transfer rate up (to atmosphere) and down (to $1 / 16$ in. thick stainless steel substrate) predicted by MELTSPREAD for the first 10 seconds of the base case pour scenario with $25 \mathrm{MW} \mathrm{m}^{-3}$ of decay heat included.

13. The effect of varying viscosity $\pm 25 \%$ from the base case value on the spreading result. ...... 15

14. The effect of varying density $\pm 25 \%$ from the base case value on the spreading result. ........ 16

15. The effect of varying the pour mass $\pm 50 \%$ from the base case value on the spreading result. 
16. The effect of varying the pour rate $\pm 50 \%$ from the base case value on the spreading

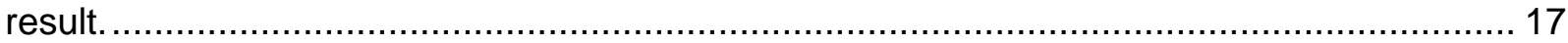

17. The effect of varying the surface tension $\pm 25 \%$ from the base case value on the

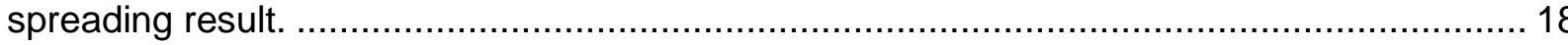




\section{Tables}

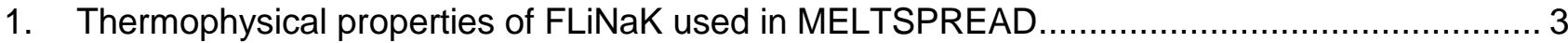

2. Spill conditions for the base case scenario in MELTSPREAD ….................................. 4

3. FLiNaK thermophysical properties for the base case scenario in MELTSPREAD .................. 5

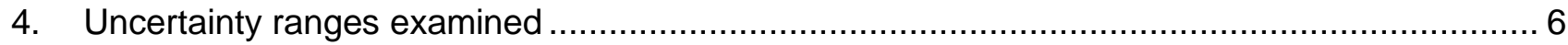




\section{Acronyms}

$\begin{array}{ll}\text { BWR } & \text { Boiling water reactor } \\ \text { EPR } & \text { Evolutionary Power Reactor } \\ \text { FLiNaK } & \text { LiF-NaF-KF, 46.5-11.5-42 mol \% } \\ \text { MSR } & \text { Molten salt reactor }\end{array}$




\begin{abstract}
This report summarizes spreading and heat transfer results for molten salt pouring onto a flat stainless steel substrate that were calculated using MELTSPREAD to gain insight into bulk salt behavior during a molten salt spill accident. MELTSPREAD was developed at Argonne to model the one-dimensional flow and freezing behavior of molten corium and is being applied to model molten salts for the first time as part of this work. An uncertainty analysis of thermophysical properties and spill conditions was performed using MELTSPREAD to determine which properties and conditions have the greatest impact on model outcome. The model was run with and without the inclusion of decay heat. Eutectic FLiNaK was used as the salt composition because it is wellcharacterized and appropriate for model development. Small salt volumes were used for the initial model runs described in this report so that the model results can be compared to the results from ongoing experiments on molten salt spreading and heat transfer currently being conducted at Argonne at a benchtop scale.
\end{abstract}

The spreading of a small volume of FLiNaK $(50 \mathrm{~mL})$ was found to be limited by the balance between the molten salt surface tension and gravity and not by freezing for the pour conditions and assumed mechanisms of heat transfer in the model. Heat transfer from the salt was highly inefficient to due to its low thermal conductivity, high heat capacity, and high heat of fusion and varying these properties had no effect on the spreading behavior. Changing the viscosity and density of the salt slightly affected the spreading behavior. Setting the salt surface tension to approximately zero to simulate the salt wetting the substrate had the greatest effect on the spreading behavior and this increased both the spreading velocity and overall spreading area. Including decay heat in the model had a significant effect on the long-term cooling behavior of the salt but had no effect on the overall spreading behavior.

Future effort should involve modeling a larger volume of molten salt to represent a reactor case spill scenario because the spreading behavior of large volumes of salt may differ from the small volumes that were the focus of this document. 


\section{Introduction}

\section{$1.1 \quad$ Motivation}

Demonstrating reactor safety is an essential part of the licensing process and includes determining the potential radiological consequences of identified accident scenarios. A common postulated accident scenario for many molten salt reactor (MSR) concepts involves a rupture within the primary loop that leads to molten fuel salt spilling onto the reactor containment floor. The containment floor of an MSR will likely be lined with a protective material (e.g., stainless steel) to prevent spilled molten salt from contacting concrete or other sensitive material below. Some MSR designs are considering using a sloped catch pan that would guide spilled molten salt to a vertical drain that leads to a passively cooled drain tank. The extent of molten salt spreading on the catch pan and the heat transfer efficiency from the salt to its surroundings will influence the radiological consequences of salt spill accidents. There remain significant uncertainties on the spreading and heat transfer behavior of molten salt that is spilled on candidate catch pan materials such as stainless steel that must be known to reliably model this process.

The spreading behavior of spilled molten salt within a defined containment geometry is important to understand because it will determine the extent to which radionuclide-bearing salt is dispersed within the reactor building. The extent of lateral spreading will either be limited by salt freezing or by the balance between the surface tension of the molten salt and gravity. The extent of spreading also determines the surface area of the salt that is in contact with the underlying structure and the surface area that is exposed to the atmosphere. A larger surface area in contact with the underlying structure will lead to faster salt cooling. A larger surface area of molten salt in contact with the atmosphere will lead to a higher vapor release rate.

It is also important to predict the heat transfer behavior of spilled molten salt to its surroundings for safety analyses. Radionuclide volatilization from a molten salt pool is predominantly halted when the salt surface freezes. In addition, the duration that the pool stays molten must be known to predict whether the protective underlying structural material contacted by the salt pool will maintain its integrity. Finally, the heat transfer efficiency must be known to develop the strategy for decay heat removal and to understand the potential consequences of an uncontrolled rise in salt temperature. These consequences may include increased vaporization and transport of volatile radionuclides (e.g., cesium and iodine), the generation and release of corrosive gaseous fluoride or chloride species, and the heating and possible degassing of the concrete beneath the catch pan.

Models on molten salt spreading and heat transfer are needed to predict the potential consequences of salt spill accidents. The MELSTSPREAD code can predict the one-dimensional gravity-driven flow and freezing behavior of molten materials in defined containment geometries (Farmer, 2017). Originally developed at Argonne to investigate the liner vulnerability of the Mark I boiling water reactor (BWR) containment system, MELTSPREAD has since been upgraded and applied to additional reactor designs including the Evolutionary Power Reactor (EPR; Farmer, 2009) and Fukushima Daiichi (Farmer et al., 2016). As part of this work, MELTSPREAD is currently being upgraded and applied to model molten salt spreading and heat transfer. 


\subsection{Objectives and approach}

The objectives of the current work are to:

- Modify and parameterize MELTSPREAD to model the spreading and heat transfer of molten salts on stainless steel substrates.

- Use MELTSPREAD to model the spreading and heat transfer of a well-characterized molten salt composition for a base case spill condition.

- Perform an uncertainty analysis to determine the sensitivity of individual thermophysical properties and spill conditions on the model outcome.

- $\quad$ Assess the impact of decay heat on molten salt spreading and heat transfer behavior.

MELTSPREAD was employed to model the spreading and heat transfer of a small volume (i.e., $50 \mathrm{~mL}$ ) of molten salt on a flat stainless steel substrate. The spill scenario for initial model development uses a small salt volume so that the model results can be compared to the experimental results from laboratory benchtop tests on molten salt spreading and heat transfer currently being conducted at Argonne (Thomas and Jackson, 2021). Eutectic LiF-NaF-KF, 46.511.5-42 mol \%, which is commonly referred to as FLiNaK, was chosen as the salt composition for these initial tests because it has been well-characterized and the thermophysical properties required to parameterize MELTSPREAD are known. A base case spill scenario was defined and used in uncertainty analyses to determine the sensitivity of the spreading and heat transfer behavior of a spilled molten salt pool to changes in individual thermophysical properties and pour conditions. The effect of decay heat was added to the model and the results were compared to the base case scenario that excluded decay heat. Identifying the thermophysical properties that have the greatest impact on model outcome will highlight the highest priority properties that require experimental measurement and provide insight into the required analytical precision of property measurements. Separate activities are in progress at Argonne to determine the precision of several methods used to determine thermophysical and thermochemical properties of salts being considered for use in MSRs (Ebert and Rose, 2021).

A procedure to estimate the spreading area for surface tension limited spreading and heat transfer limited spreading by hand is provided in Appendix $A$.

\section{Thermophysical properties of FLiNaK used in MELTSPREAD}

The thermophysical properties of FLiNaK that were used as input in MELTSPREAD to model its spreading and heat transfer on a stainless steel substrate are provided in Table 1. All property values were obtained from Jerden, 2019 unless specified otherwise. When necessary, the property value was extrapolated outside of the applicable temperature range that is reported in Table 1. 
Table 1: Thermophysical properties of FLiNaK used in MELTSPREAD

\begin{tabular}{|c|c|c|c|}
\hline Property & Value & $\begin{array}{l}\text { Applicable } \\
\text { temp. range } \\
(\mathrm{K})^{\mathrm{a}}\end{array}$ & Reference $^{\mathbf{b}}$ \\
\hline Composition (mol \%) & $(\mathrm{LiF})_{0.465}(\mathrm{KF})_{0.42}(\mathrm{NaF})_{0.115}$ & - & - \\
\hline Melting point $(\mathrm{K})$ & 729 & - & (Lichtenstein et al., 2020) \\
\hline $\begin{array}{l}\text { Assumed melting temp. } \\
\text { range }(\mathrm{K})\end{array}$ & $729-730$ & - & - \\
\hline Boiling point $(\mathrm{K})$ & 1843.2 & - & - \\
\hline $\begin{array}{l}\text { Liquid density } \\
\left(\mathrm{g} \mathrm{cm}^{-3}\right)(\mathrm{T}: \mathrm{K})\end{array}$ & $2.6-\left(6.2 \times 10^{-4}\right) T$ & $933-1163$ & - \\
\hline $\begin{array}{l}\text { Solid density } \\
\left(\mathrm{g} \mathrm{cm}^{-3}\right)\end{array}$ & 2.199 & - & (Chapdelaine, 2017) \\
\hline $\begin{array}{l}\text { Dynamic viscosity } \\
\left(\mathrm{mN} \mathrm{s} \mathrm{m}^{-2}\right)(\mathrm{T}: \mathrm{K})\end{array}$ & $\left(2.49 \times 10^{-2}\right) 10^{(1944 / T)}$ & $773-1163$ & $\begin{array}{c}\text { (Chrenkova et al., 2003; } \\
\text { Serrano-López et al., } \\
\text { 2013) }\end{array}$ \\
\hline $\begin{array}{l}\text { Liquid heat capacity } \\
\qquad\left(\mathrm{J} \mathrm{K}^{-1} \mathrm{~mol}^{-1}\right)\end{array}$ & $40+\left(4.4 \times 10^{-2}\right) T$ & - & - \\
\hline $\begin{array}{l}\text { Solid heat capacityc } \\
\qquad\left(\mathrm{J} \mathrm{K}^{-1} \mathrm{~mol}^{-1}\right)\end{array}$ & $40+\left(4.4 \times 10^{-2}\right) T$ & - & - \\
\hline 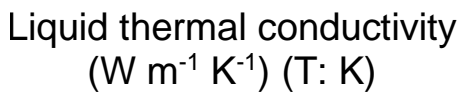 & $-0.35+\left(1.3 \times 10^{-3}\right) T$ & $773-973$ & - \\
\hline $\begin{array}{l}\text { Solid thermal conductivity } \\
\qquad\left(\mathrm{W} \mathrm{m}^{-1} \mathrm{~K}^{-1}\right)(\mathrm{T}: \mathrm{K})\end{array}$ & $-0.35+\left(1.3 \times 10^{-3}\right) T$ & - & - \\
\hline $\begin{array}{l}\text { Latent heat of fusion } \\
\qquad\left(\mathrm{J} \mathrm{g}^{-1}\right)\end{array}$ & 1661 & - & (Williams, 2006) \\
\hline $\begin{array}{l}\text { Surface tension } \\
\qquad\left(\mathrm{N} \mathrm{m}^{-1}\right)\end{array}$ & $0.2726-\left(1.014 \times 10^{-4}\right) T$ & $770-1040$ & (Sohal et al., 2013) \\
\hline $\begin{array}{l}\text { Liquid volume expansion } \\
\text { coefficient }\left(\mathrm{K}^{-1}\right)\end{array}$ & $\begin{array}{c}3.4 \times 10^{-4} \\
\text { (average value) }\end{array}$ & - & (Anderson et al., 2015) \\
\hline Radiative emissivity & Unknown. assume 1 & - & $\begin{array}{l}\text { (Ambrosek et al., 2009; } \\
\text { Yoder et al., 2014) }\end{array}$ \\
\hline
\end{tabular}




\section{MELTSPREAD model input and description}

\subsection{Model description and spill conditions of the base case scenario}

The modeled spill scenario involved molten FLiNaK with an assumed jet radius of $5 \mathrm{~mm}$ impinging on a flat stainless steel substrate and the spreading geometry was assumed to be circular (Figure 1). The conditions of the spill that were used as input in the MELTSPREAD model are provided in Table 2.

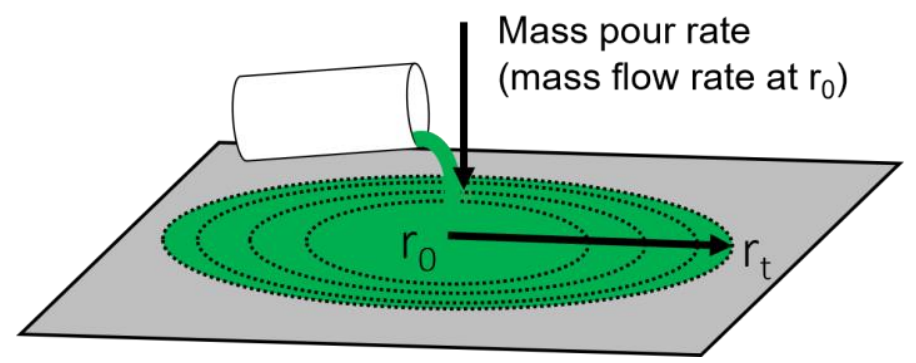

Figure 1: Schematic of the radial spreading of molten salt poured onto a flat substrate that was modeled using MELTSPREAD

Table 2: Spill conditions for the base case scenario in MELTSPREAD

\begin{tabular}{lc}
\hline \multicolumn{1}{c}{ Spill condition } & Value \\
\hline Pour temperature & $650^{\circ} \mathrm{C}$ \\
Pour volume & $50 \mathrm{~mL}$ \\
Corresponding pour mass ${ }^{\mathrm{a}}$ & $101 \mathrm{~g}$ \\
Volumetric pour rate & $10 \mathrm{~mL} \mathrm{~s}^{-1}$ \\
Corresponding mass flow rate & $20.2 \mathrm{~g} \mathrm{~s}^{-1}$ \\
Substrate material & Stainless steel \\
Substrate thickness & $1 / 16$ in. $(1.59 \mathrm{~mm})$ \\
Radius of pour jet & $5 \mathrm{~mm}$ \\
Decay heat level & None \\
\hline a Based on liquid density value used for base case.
\end{tabular}

A region within a circular boundary was discretized with radial nodes for the spreading analysis, and the radius of the outer boundary $(15 \mathrm{~cm})$ was confirmed to be adequate to accommodate the expected spreading surface of the base case scenario when limited by surface tension. Each radial increment within the circular boundary corresponded to $1 \mathrm{~cm}^{2}$ in surface area. The result was a mesh with 707 radial annular nodes. Variations on time step and mesh size were explored during model construction to ensure that the results converged.

The bulk freezing model in MELTSPREAD was used to calculate salt cool down and solidification during spreading, and the heat transfer to the stainless steel substrate was modeled using the 
Dittus-Boelter forced convection heat transfer coefficient. A description of how spreading and heat transfer are calculated in MELTSPREAD is provided in Farmer, 2017. The stainless steel substrate was assumed to be adiabatic (i.e., insulated) on the back side. The thermophysical properties were fixed throughout the calculation as the salt cooled and only changed due to a phase change (e.g., liquid to solid). The emissivity of the inner walls of the containment structure was assumed to be 0.3 , which is approximately the emissivity of stainless steel. To account for changes in viscosity at the freezing point, the solid fraction in the molten salt was assumed to vary linearly over the assumed freezing temperature range of $729-730 \mathrm{~K}$ (see Table 1 ). The enhancement in viscosity due to the buildup of solids in the molten salt was calculated using the Ishii-Zuber correlation.

The FLiNaK thermophysical properties that were input into MELTSPREAD for the base case scenario are provided in Table 3.

Table 3: FLiNaK thermophysical properties for the base case scenario in MELTSPREAD

\begin{tabular}{|c|c|c|}
\hline Spill condition & Value & Notes \\
\hline Liquid density & $2.02 \mathrm{~g} \mathrm{~cm}^{-3}$ & $\begin{array}{l}\text { Calculated at } 933 \mathrm{~K} \text { (i.e., within } \\
\text { correlation range in Table 1) }\end{array}$ \\
\hline Solid density & $2.20 \mathrm{~g} \mathrm{~cm}^{-3}$ & \\
\hline Dynamic viscosity & $3.18 \times 10^{-3} \mathrm{~kg} \mathrm{~m}^{-1} \mathrm{~s}^{-1}$ & \\
\hline Liquid specific heat & $1952 \mathrm{~J} \mathrm{~kg}^{-1} \mathrm{~K}^{-1}$ & \\
\hline Solid specific heat & $1952 \mathrm{~J} \mathrm{~kg}^{-1} \mathrm{~K}^{-1}$ & $\begin{array}{l}\text { Unknown; assumed to equal liquid } \\
\text { value }\end{array}$ \\
\hline Liquid thermal conductivity & $0.85 \mathrm{~W} \mathrm{~m}^{-1} \mathrm{~K}^{-1}$ & \\
\hline Solid thermal conductivity & $0.85 \mathrm{~W} \mathrm{~m}^{-1} \mathrm{~K}^{-1}$ & $\begin{array}{l}\text { Unknown; assumed to equal liquid } \\
\text { value }\end{array}$ \\
\hline Latent heat of fusion & $1.661 \times 10^{6} \mathrm{~J} \mathrm{~kg}^{-1}$ & \\
\hline Surface tension & $0.179 \mathrm{~N} \mathrm{~m}^{-1}$ & \\
\hline Radiation emissivity & 1.0 & Assumed value \\
\hline
\end{tabular}

\subsection{Uncertainty analysis}

The uncertainty ranges of pour conditions and thermophysical properties that were examined are shown in Table 4. The effect of changing the property value or condition on the model outcome was tested for each property or condition individually and compared to the results from the base case scenario. When the effect of initial salt temperature was analyzed, the thermophysical property values were not changed from the base case values (i.e., those at $650^{\circ} \mathrm{C}$ ) to reflect a change in thermophysical properties with temperature. 
Table 4: Uncertainty ranges examined

\begin{tabular}{|c|c|c|c|}
\hline Parameter & $\begin{array}{l}\text { Uncertainty } \\
\text { range }\end{array}$ & Minimum Value & Maximum Value \\
\hline Pour temperature & $\pm 150^{\circ} \mathrm{C}$ & $500^{\circ} \mathrm{C}$ & $800^{\circ} \mathrm{C}$ \\
\hline Pour volume & $\pm 25 \mathrm{~mL}$ & $25 \mathrm{~mL}$ & $75 \mathrm{~mL}$ \\
\hline Corresponding pour mass & $\pm 50.5 \mathrm{~g}$ & $50.5 \mathrm{~g}$ & $151.5 \mathrm{~g}$ \\
\hline Volumetric pour rate & $\pm 5 \mathrm{~mL} \mathrm{~s}^{-1}$ & $5 \mathrm{~mL} \mathrm{~s}^{-1}$ & $15 \mathrm{~mL} \mathrm{~s}^{-1}$ \\
\hline Corresponding mass flow rate & $\pm 10.1 \mathrm{~g} \mathrm{~s}^{-1}$ & $10.1 \mathrm{~g} \mathrm{~s}^{-1}$ & $30.3 \mathrm{~g} \mathrm{~s}^{-1}$ \\
\hline Liquid density & $\pm 25 \%$ & $2.525 \mathrm{~g} \mathrm{~cm}^{-3}$ & $1.515 \mathrm{~g} \mathrm{~cm}^{-3}$ \\
\hline Dynamic viscosity & $\pm 25 \%$ & $2.385 \times 10^{-3} \mathrm{~kg} \mathrm{~m}^{-1} \mathrm{~s}^{-1}$ & $3.975 \times 10^{-3} \mathrm{~kg} \mathrm{~m}^{-1} \mathrm{~s}^{-1}$ \\
\hline Liquid specific heat & $\pm 25 \%$ & $1464 \mathrm{~J} \mathrm{~kg}^{-1} \mathrm{~K}^{-1}$ & $2440 \mathrm{~J} \mathrm{~kg}^{-1} \mathrm{~K}^{-1}$ \\
\hline Liquid thermal conductivity & $\pm 25 \%$ & $0.6375 \mathrm{~W} \mathrm{~m}^{-1} \mathrm{~K}^{-1}$ & $1.0625 \mathrm{~W} \mathrm{~m}^{-1} \mathrm{~K}^{-1}$ \\
\hline Latent heat of fusion* & $\pm 25 \%$ & $1.246 \times 10^{6} \mathrm{~J} \mathrm{~kg}^{-1}$ & $2.076 \times 10^{6} \mathrm{~J} \mathrm{~kg}^{-1}$ \\
\hline Surface tension & $\pm 25 \%$ & $0.134 \mathrm{~N} \mathrm{~m}^{-1}$ & $0.224 \mathrm{~N} \mathrm{~m}^{-1}$ \\
\hline Radiation emissivity & $\mathrm{n} / \mathrm{a}$ & 0.9 & 1.0 \\
\hline Substrate thickness & $\mathrm{n} / \mathrm{a}$ & $1 / 16$ in. $(1.59 \mathrm{~mm})$ & $1 / 4$ in. $(6.35 \mathrm{~mm})$ \\
\hline Decay heat & $\mathrm{n} / \mathrm{a}$ & $0 \mathrm{MW} \mathrm{m}^{-3}$ & $25 \mathrm{MW} \mathrm{m}^{-3}$ \\
\hline
\end{tabular}

\section{MELTSPREAD model results}

\subsection{Base case spreading results}

The extent of spreading is quantified as the melt leading edge radius versus the time since the molten salt first impinged on the stainless steel substrate for all spreading results in this document. The base case spreading results $\left(50 \mathrm{~mL}\right.$ of FLiNaK at an initial temperature of $650{ }^{\circ} \mathrm{C}$ pouring at a rate of $10 \mathrm{~mL} \mathrm{~s}^{-1}$ onto a $1 / 16$ in. thick stainless steel substrate) are plotted in Figure 2 . The spatial resolution of the spreading results is limited by the meshing node size, which is $1 \mathrm{~cm}^{2}$.

Spreading is predicted to stop when the melt pool reaches a radius of $6.95 \mathrm{~cm}$ (i.e., an area of $152 \mathrm{~cm}^{2}$ ) and to last a duration of approximately 6 seconds. The FLiNaK is still molten after spreading stops. The spreading is limited by the balance between the surface tension of the salt and gravity and not by salt freezing. The method for estimating melt thickness for surface tension limited spreading (which is described in Appendix A Section A.2) and the properties listed in Table 3 were used to predict a minimum spreading thickness of $4.25 \mathrm{~mm}$. A minimum spreading thickness of $4.25 \mathrm{~mm}$ and a total pour volume of $50 \mathrm{~mL}$ corresponds to a maximum spreading area of $118 \mathrm{~cm}^{2}$, which is smaller than the area of $152 \mathrm{~cm}^{2}$ that was calculated by MELTSPREAD. The discrepancy between the spreading area determined by using MELTSPREAD and the maximum spreading area estimate for spreading limited by surface tension occurs because the minimum thickness model neglects the effects of melt inertia during spreading. Inertia causes the molten salt to spread further than the minimum depth at which surface tension balances gravity. This over-spreading creates a negative pressure gradient exerted on the molten salt pool that attempts to retract the pool to a smaller spreading area. However, the combination of the negative pressure gradient and viscous effects do not counterbalance the effect of inertia, which results in a final configuration that exceeds the maximum spreading area estimate. 


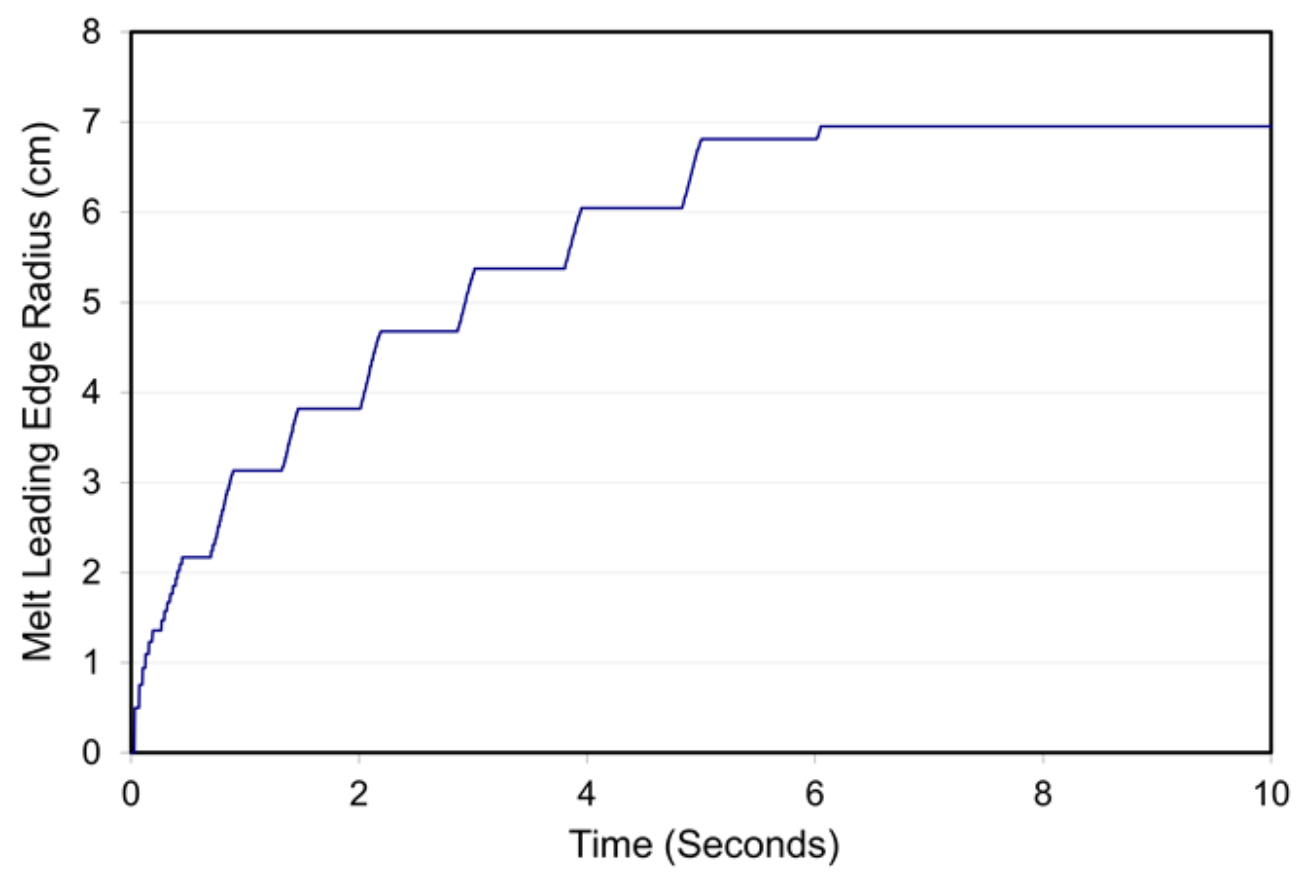

Figure 2: The extent of spreading of molten FLiNaK on a flat stainless steel substrate for the base case condition plotted as the leading edge radius as a function of time.

A noticeable feature of the spreading result in Figure 2 is the stepping behavior of the spread radius as a function of time. The stepping behavior occurs because spreading is initially stopped when the depth of the leading edge falls below the minimum depth that is determined by the balance between the surface tension of the molten salt pool and gravity. This phenomenon produces a hydraulic wave that is reflected back towards the impingement zone. Subsequently, the molten salt begins to spread and again spreads beyond the limit governed by the balance between surface tension and gravity. In this way, the repeated spreading and stopping behavior creates the stepping feature in Figure 2. The stepping behavior of the leading edge position over time is consistent with spreading behavior that occurs when the melt does not wet the substrate. Spreading behavior is considerably different when the melt does wet the substrate; this is discussed further in Section 4.5.

Due to the high heat capacity and high heat of fusion of FLiNaK, the melt must cover more area to increase the heat rejection to the point where the molten salt would freeze during spreading. The thickness of the stainless steel substrate also influences the amount of heat that can be extracted from the salt during spreading. Employing a thicker substrate material would increase the amount of heat extracted from the salt during spreading. This effect on heat transfer behavior is explored in Section 4.2.

\subsection{Base case heat transfer results}

The integrated heat transfer rate up to the atmosphere, down to the $1 / 16$ in. thick stainless steel substrate, and the total heat transfer rate that was predicted by MELTSPREAD for the base case pour scenario are plotted in Figure 3. The stainless steel substrate acts as a heat sink for approximately the first minute after the salt was poured, as shown by the high heat transfer rate from the salt to the substrate in Figure 3. After this time, the heat that is extracted from the salt to 


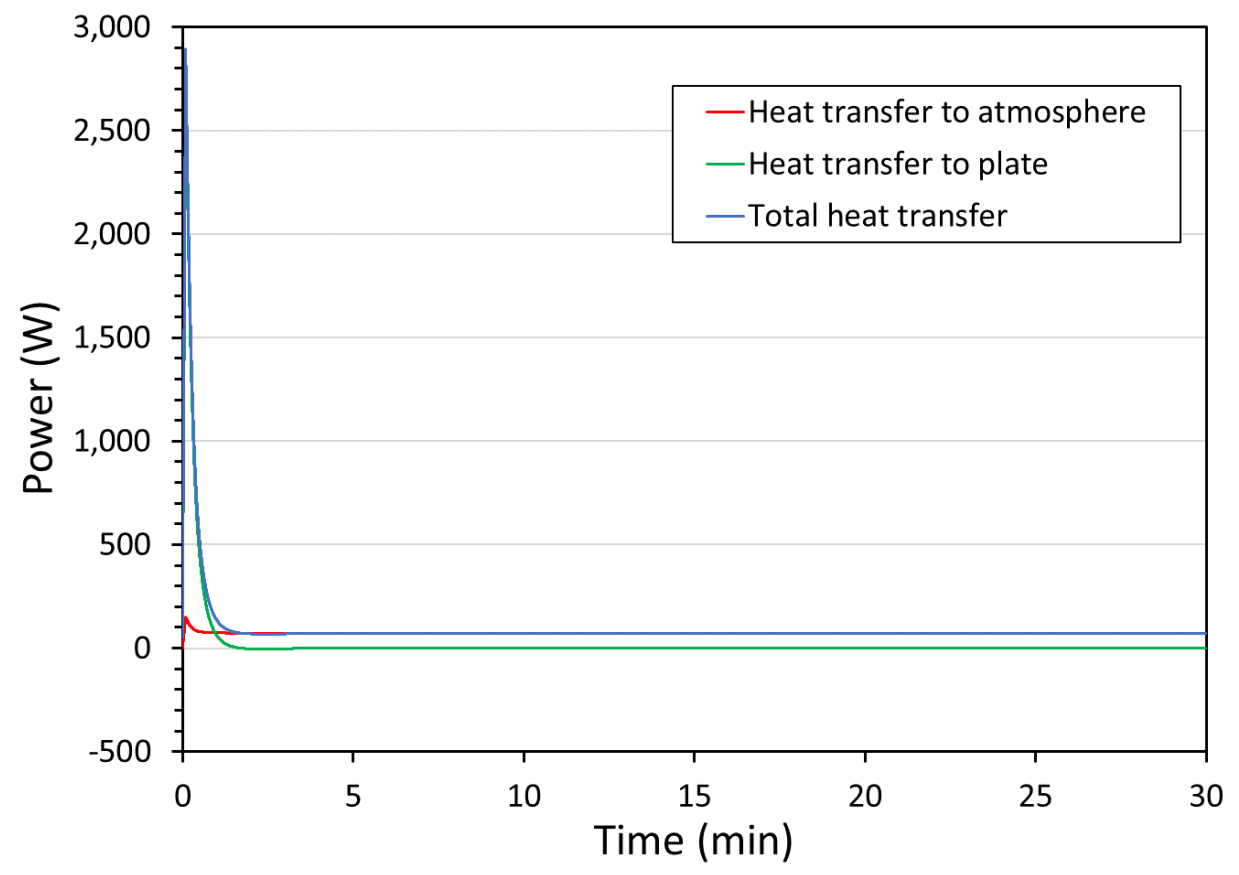

Figure 3: Integrated heat transfer rate up (to atmosphere) and down (to $1 / 16$ in. thick stainless steel substrate) predicted by MELTSPREAD for the base case pour scenario.

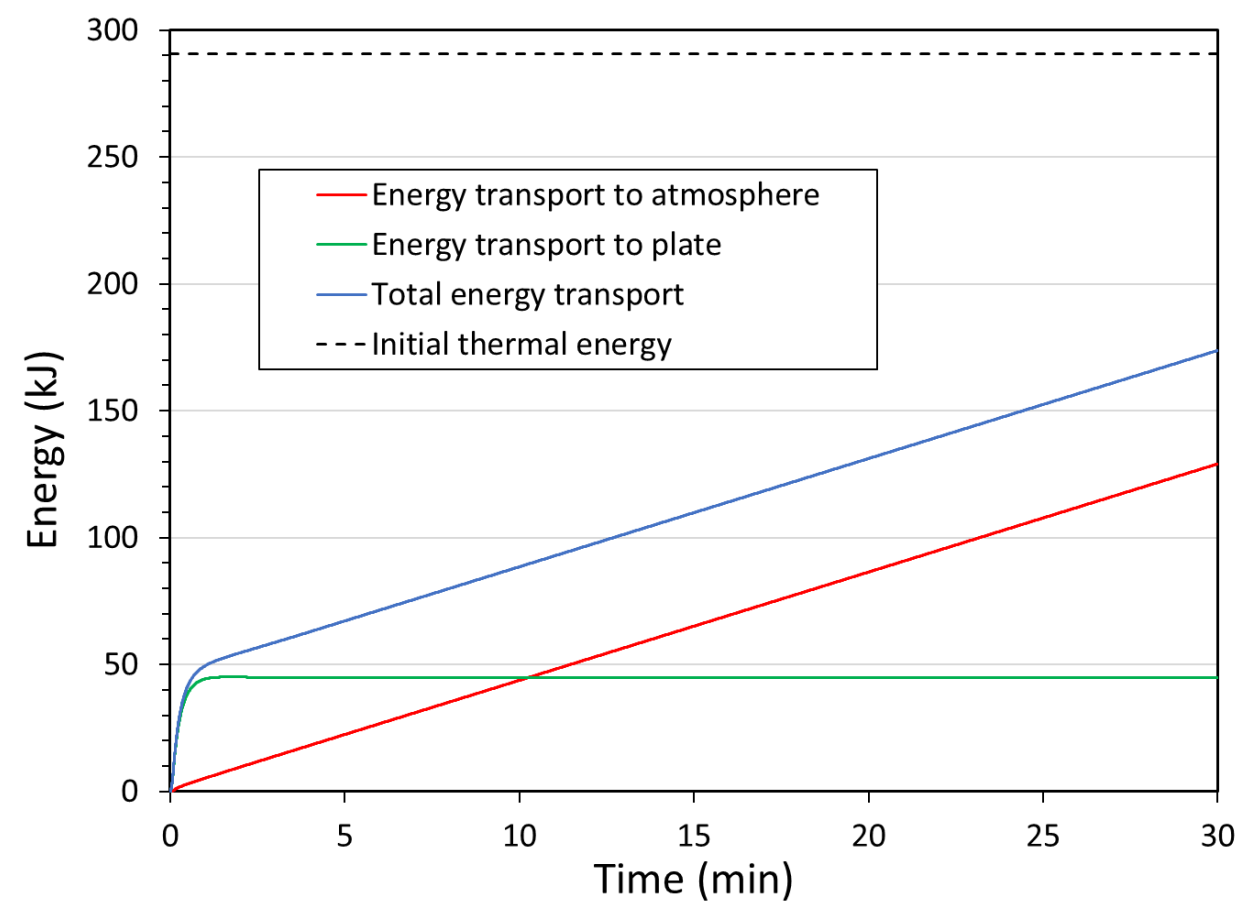

Figure 4: Integrated energy transfer up (to atmosphere) and down (to $1 / 16$ in. thick stainless steel substrate) predicted by MELTSPREAD for the base case pour scenario.

the substrate goes to zero. The back side of the substrate is modeled as adiabatic (i.e., insulated) in MELTSPREAD. Thus, heat transfer to the plate ceases once the plate temperature throughout 
its depth reaches the local salt temperature. After this time, the only heat rejection pathway is upwards by radiation heat transfer to the surrounding containment structure. If the catch pan of an MSR is not insulated or can reject heat to an underlying structure, the heat transfer results predicted by MELTSPREAD in this work will under-predict the heat retention in the stainless steel substrate and underlying medium. However, if the backing behind the catch pan in an MSR is made of concrete, then the results predicted by MELTSPREAD should be representative due to the low thermal conductivity and conduction heat transfer properties of concrete. As the salt cools and the underlying plate heats up, heat is eventually extracted out of the salt by conduction to the upper surface where it is rejected by radiation heat transfer. The only upward heat transfer pathway in MELTSPREAD under dry conditions is radiation. Natural convective cooling is not taken into account in the MELTSPREAD model, which likely leads to an under-prediction of late-phase heat rejection.

The integrated energy removal up to the atmosphere, down to the $1 / 16$ in. thick stainless steel substrate, and the total energy removal that was predicted by MELTSPREAD for the base case pour scenario are plotted in Figure 4. Thirty minutes after the salt first touched the stainless steel substrate, $174 \mathrm{~kJ}$ of the $291 \mathrm{~kJ}$ of initial thermal energy contained in the salt had been removed (Figure 4). The heat rejection from the salt is low due to the extremely low thermal conductivity of the salt. The temperature of the substrate top surface and substrate underside surface at the location of melt impact that was predicted by MELTSPREAD for the base case pour scenario are plotted in Figure 5. The temperatures of the top surface and underside surface are only separated by a few degrees throughout the entire 30-minute calculation (Figure 5). The substrate surface temperatures peak at approximately $500{ }^{\circ} \mathrm{C}$ one minute after the molten salt first impacted on the substrate. Approximately five minutes after melt impact, the substrate surface temperatures cooled to the salt freezing temperature and held at that temperature for over 30 minutes. The salt remains molten for a while after spreading has stopped and still has some liquid content 30 minutes after impact onto the stainless steel substrate.

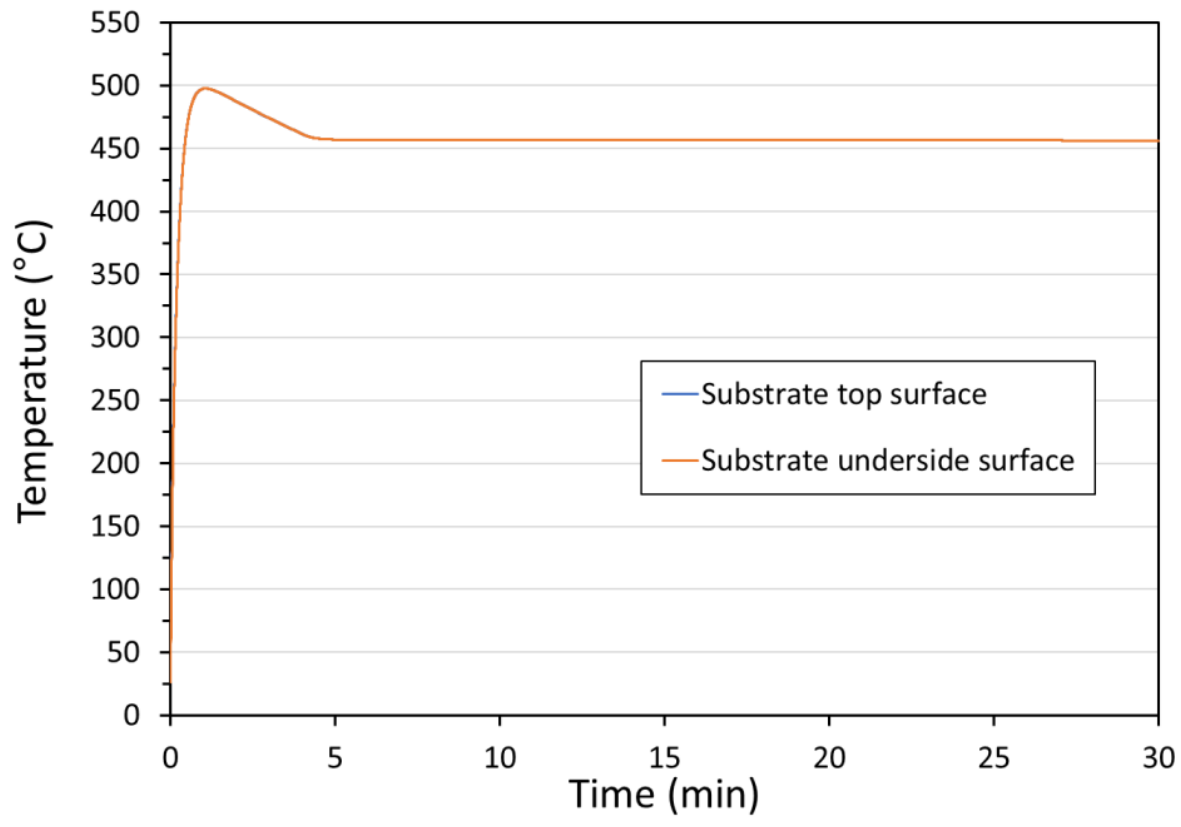

Figure 5: The surface temperatures of the top and underside of the $1 / 16$ in. thick stainless steel substrate at the location of melt impact $\left(r_{0}\right)$ predicted by MELTSPREAD for the base case pour scenario. The temperatures of the top surface and underside surface are within a few degrees. 


\subsection{Effect of substrate thickness on heat transfer and spreading}

The effect of substrate thickness on the heat removal efficiency from molten FLiNaK on stainless steel was explored by repeating the MELTSPREAD calculations for the base case pour conditions but using a substrate thickness of $1 / 4 \mathrm{in}$. instead of $1 / 16$ in. The integrated heat transfer rate up to the atmosphere, down to the $1 / 4$ in. thick stainless steel substrate, and the total heat transfer rate that was predicted by MELTSPREAD for the base case pour scenario are plotted in Figure 6 . The stainless steel substrate acts as a heat sink for approximately the first five minutes of contact with the molten salt, after which time heat ceases to be extracted from the salt to the substrate (Figure 6). The heat rejection mechanism is then solely due to radiation from the surface of the salt.

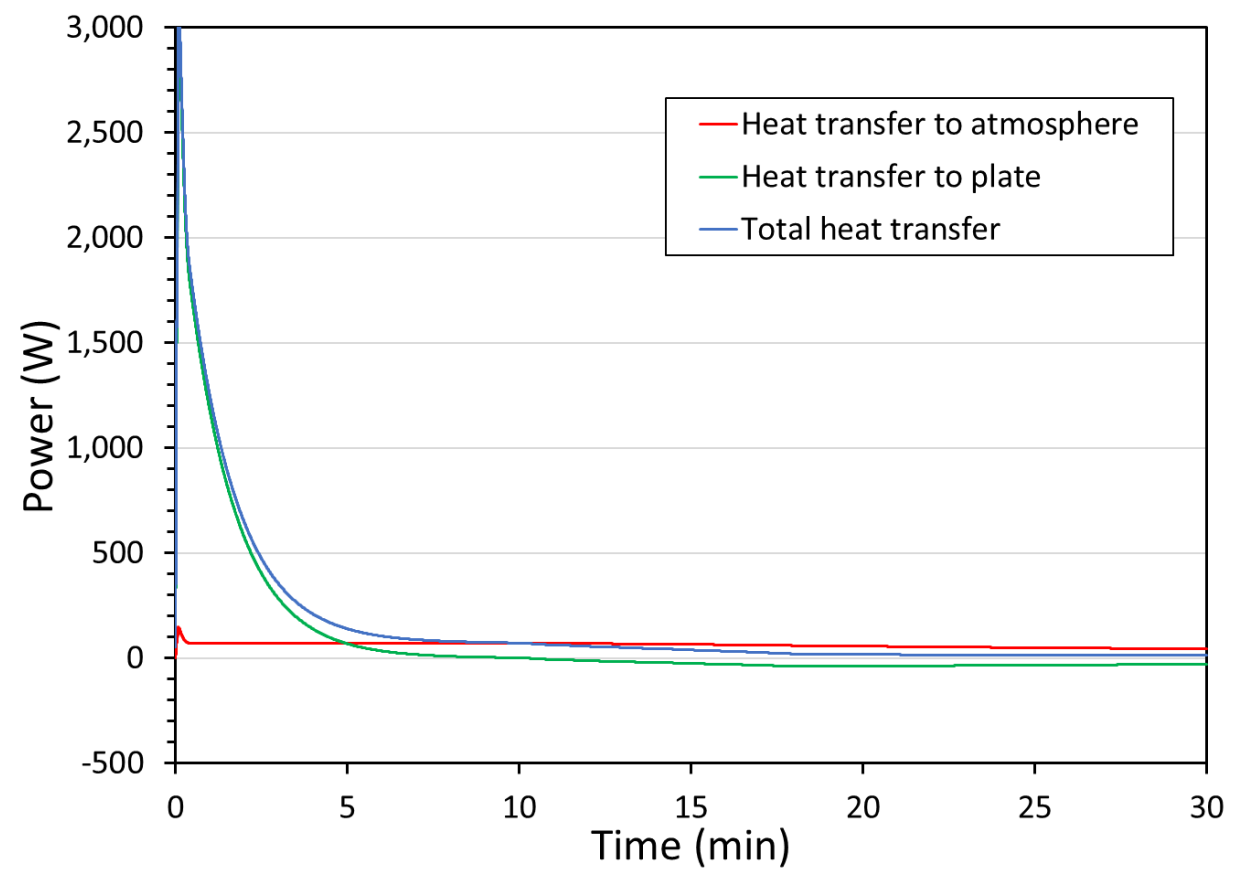

Figure 6: Integrated heat transfer rate up (to atmosphere) and down (to $1 / 4$ in. thick stainless steel substrate) predicted by MELTSPREAD for the base case pour conditions.

The integrated energy removal up to the atmosphere, down to the $1 / 4$ in. thick stainless steel substrate, and the total energy removal that was predicted by MELTSPREAD for the base case pour conditions are plotted in Figure 7 . Thirty minutes after the salt first touched the stainless steel substrate, a total of $278 \mathrm{~kJ}$ of the available $291 \mathrm{~kJ}$ of initial heat content of the salt has been removed by heat transfer to the stainless steel substrate and atmosphere (Figure 7).

The temperature of the $1 / 4$ in. thick substrate top surface and underside surface at the location of molten salt impact that was predicted by MELTSPREAD for the base case pour conditions are plotted in Figure 8 . The $1 / 4$ in. thick substrate heats at a slower rate than the $1 / 16$ in. thick substrate for the same pour conditions. Approximately five minutes after melt impact, the substrate surface temperatures have both reached the salt freezing temperature and hold at that temperature for approximately 15 minutes (Figure 8). Approximately 20 minutes after melt impact on the substrate, sufficient heat has been extracted from the salt to render it completely solid. Thereafter, the substrate begins to gradually cool due to heat extraction from the substrate that is dissipated by 
conduction through the salt and eventual radiant heat transfer to the atmosphere. Cooling of the substrate by this mechanism is apparent by the fact that the upper surface temperature of the stainless steel substrate remains lower than the temperature of the underside of the substrate (Figure 8).

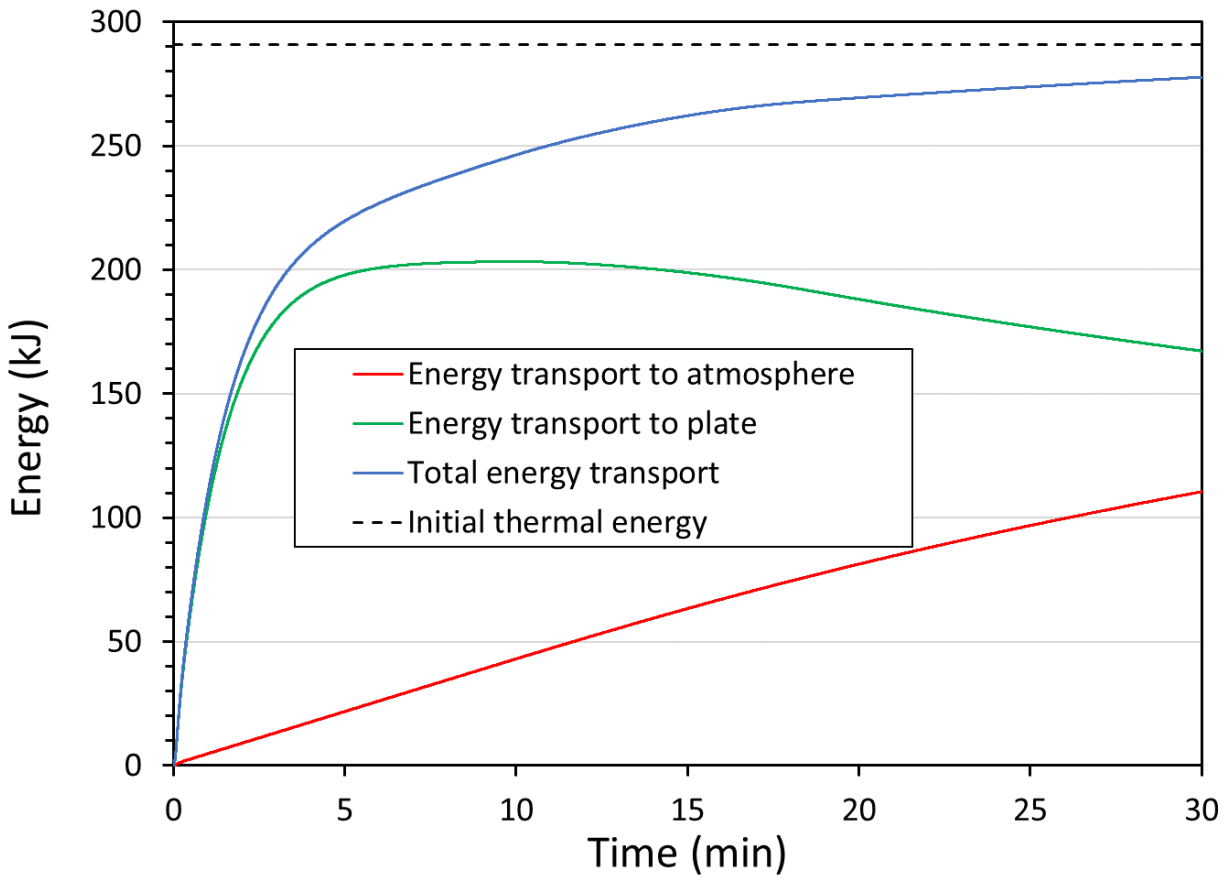

Figure 7: Integrated energy transfer up (to the atmosphere) and down (to the $1 / 4$ in. thick stainless steel substrate) predicted by MELTSPREAD for the base case pour conditions.

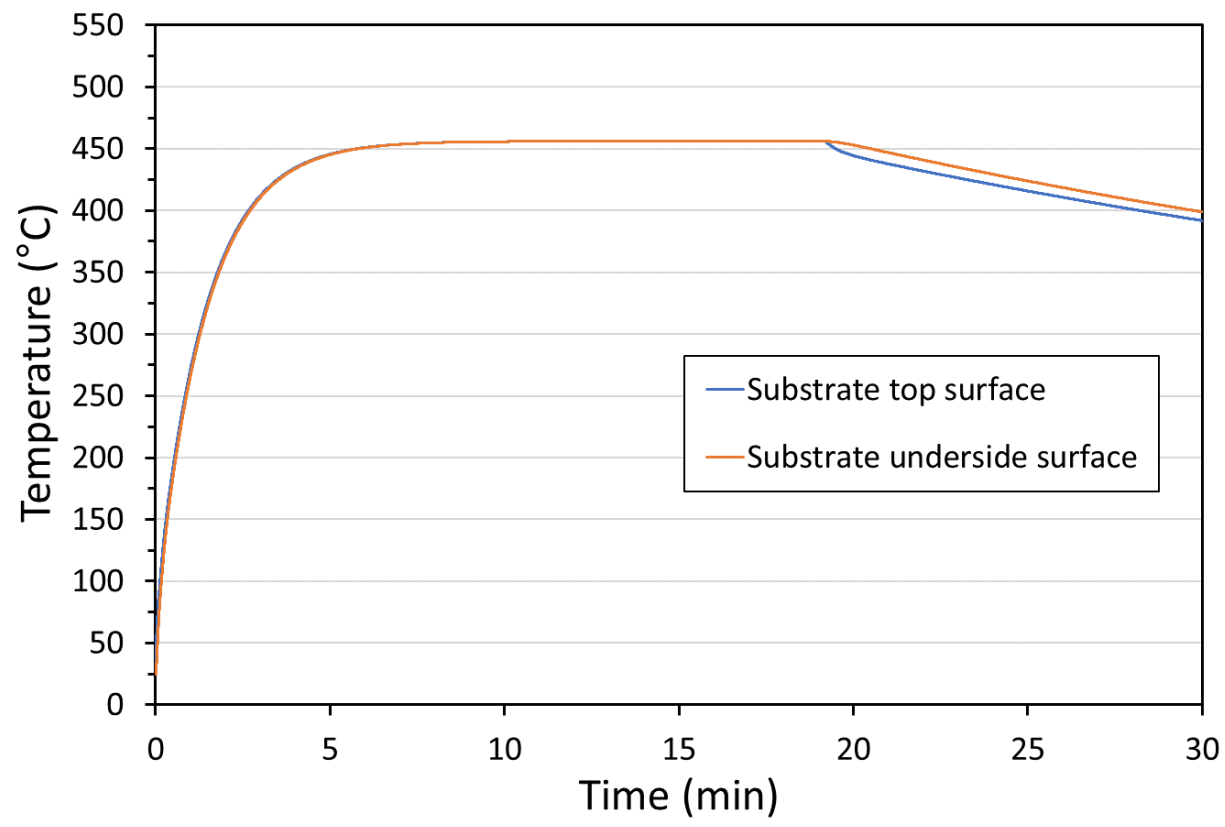

Figure 8: The surface temperatures of the top and underside of the $1 / 4$ in. thick stainless steel substrate at the impact location $\left(r_{0}\right)$ predicted by MELTSPREAD for the base case pour conditions. 
While increasing the substrate thickness from $1 / 16$ in. to $1 / 4$ in. increased the amount of heat that was absorbed by the substrate, it did not affect the spreading behavior of the molten salt.

\subsection{Effect of decay heat on heat transfer and spreading}

The decay heat that is generated in the spilled salt pool will depend on the power density of the fuel salt. The total amount of power at shutdown for an MSR is expected to be $5 \%$ of the nominal power, which is less than solid fuel reactors because fission products are continuously removed from the salt (Allibert et al., 2016). For a large reactor (e.g., $2500 \mathrm{MWth}$ ), the power densities of MSR fuel salts at shutdown will range from 20 to $50 \mathrm{MW} \mathrm{m}^{-3}$ (Thomas and Jerden, 2020). For the molten salt fast reactor (MSRF), the power of the heat sources in the fuel salt is expected to decrease rapidly, by approximately ten-fold one day after shutdown (Brovchenko et al., 2013). This implies that several tens of megawatts will need to be rejected from the salt pool for at least a day after a spill.

The effect of decay heat on the heat removal efficiency from molten FLiNaK on stainless steel was explored by repeating the MELTSPREAD calculations for the base case pour conditions with $25 \mathrm{MW} \mathrm{m}^{-3}$ of decay heat included. MELTSPREAD requires the decay heat to be input in terms of power per kilogram, so the volumetric power density of $25 \mathrm{MW} \mathrm{m}^{-3}$ that was chosen for assessment was converted to $12.38 \mathrm{~kW} \mathrm{~kg}^{-1}$ salt using the liquid density of FLiNaK provided in Table 3 . This power density is equivalent to $1250 \mathrm{~W}$ in $101 \mathrm{~g}(50 \mathrm{~mL})$ of molten salt. The decay heat was held at a constant value over the course of the calculation (30 minutes). The inclusion of decay heat has a large effect on the long-term cooling behavior of the salt for the base case conditions. The integrated heat transfer rate up to the atmosphere and down to the $1 / 16$ in. thick stainless steel substrate that was predicted by MELTSPREAD for the base case pour scenario with $25 \mathrm{MW} \mathrm{m}^{-3}$ of decay heat included are plotted in Figure 9.

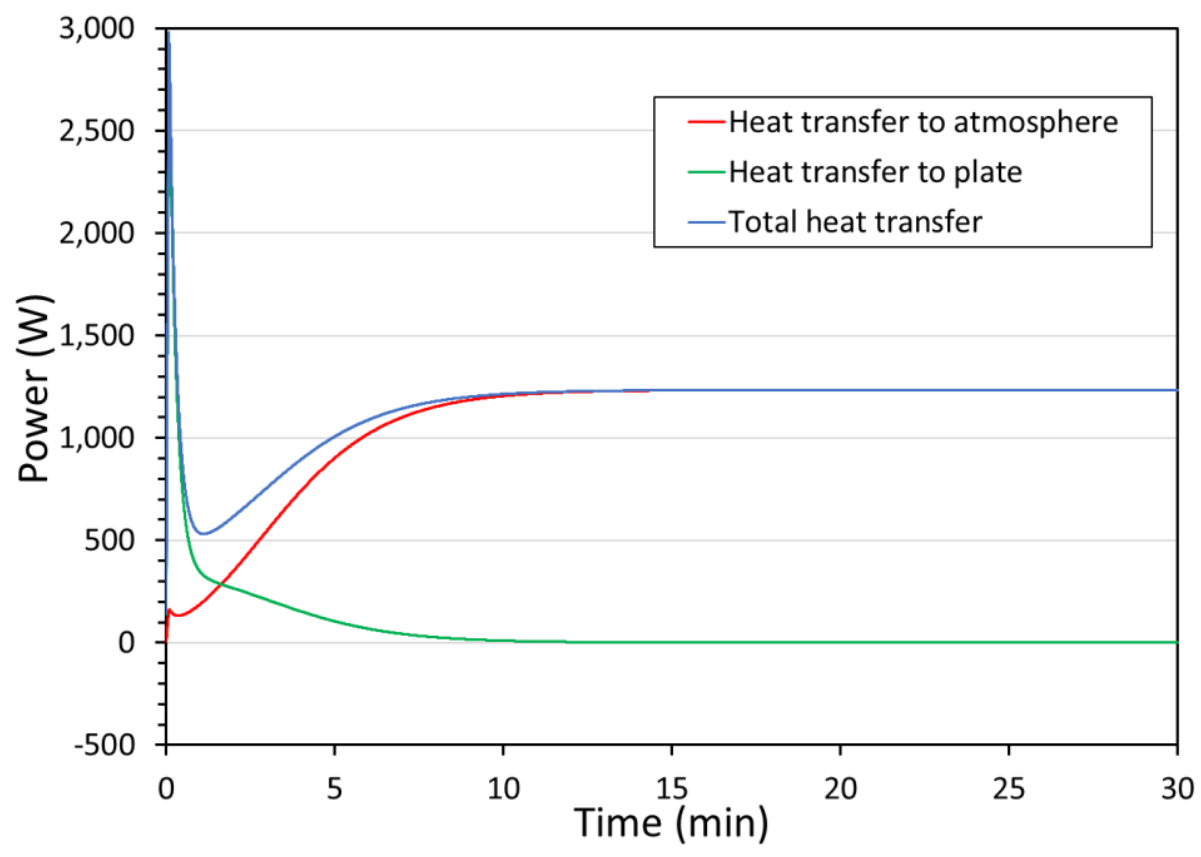

Figure 9: Integrated heat transfer rate up (to atmosphere) and down (to $1 / 16$ in. thick stainless steel substrate) predicted by MELTSPREAD for the base case pour scenario with $25 \mathrm{MW} \mathrm{m}^{-3}$ of decay heat included. 
Ten minutes after the salt was poured onto the substrate, the salt reaches a temperature at which radiation heat transfer from the salt is able to dissipate the $1250 \mathrm{~W}$ of decay heat to the atmosphere (Figure 9). The salt temperature at which this occurs is approximately $1200^{\circ} \mathrm{C}$. The stainless steel substrate concurrently heats up over those 10 minutes to the same temperature of $1200{ }^{\circ} \mathrm{C}$ (Figure 10). The temperature of the salt and the stainless steel substrate remain constant at approximately $1200^{\circ} \mathrm{C}$ for the remainder of the 30 minute calculation due to the fact that the decay heat was held constant. A decrease in decay heat with time, as would be expected for radionuclidebearing salt that spilled from a reactor, would lead to decreasing salt and substrate temperatures with time.

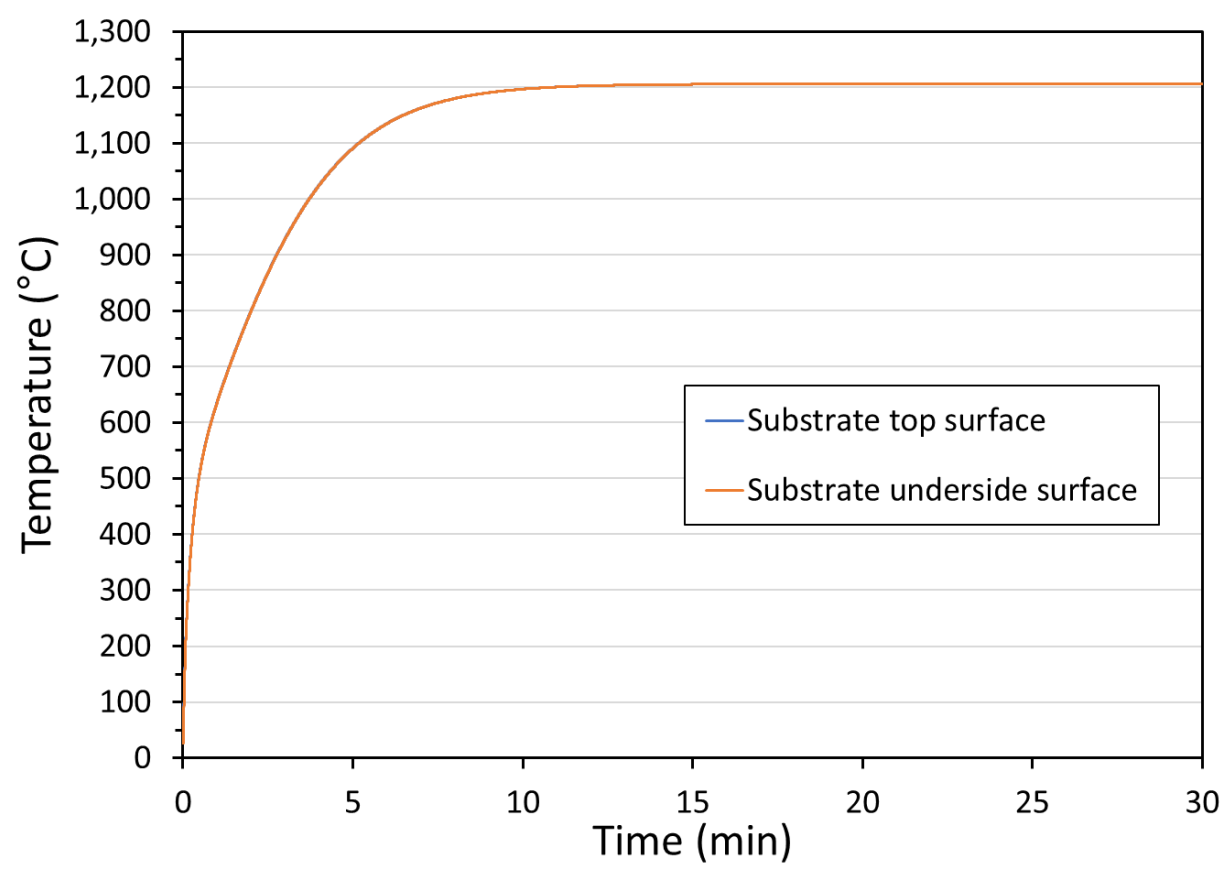

Figure 10: The surface temperatures of the top and underside of the $1 / 16$ in. thick stainless steel substrate at the location of melt impact $\left(r_{0}\right)$ predicted by MELTSPREAD for the base case pour scenario with $25 \mathrm{MW} \mathrm{m}^{-3}$ of decay heat included. The temperatures of the top surface and underside surface are only separated by a few degrees.

The integrated energy removal up to the atmosphere, down to the $1 / 16$ in.- thick stainless steel substrate, and the total energy removal that was predicted by MELTSPREAD for the base case pour conditions with $25 \mathrm{MW} \mathrm{m}^{-3}$ of decay heat included are plotted in Figure 11. The available heat content in the salt increases with time in Figure 11 (dotted line) due to the inclusion of decay heat in the model.

The inclusion of decay heat in the base case model had no effect of the spreading results for the base case pour scenario. The reason for this can be explained using the results presented in Figure 12, which show the integrated heat transfer rates to the substrate and the atmosphere for the first 10 seconds of the base case pour scenario with decay heat included. The amount of decay heat in the salt (dashed line in Figure 12) is less than the early transient heat transfer rate to the predominant heat sink (i.e., conduction heat transfer into the stainless steel substrate during the early spreading phase). Therefore, the salt stops spreading before decay heat has a significant influence on the overall heat transfer behavior. 


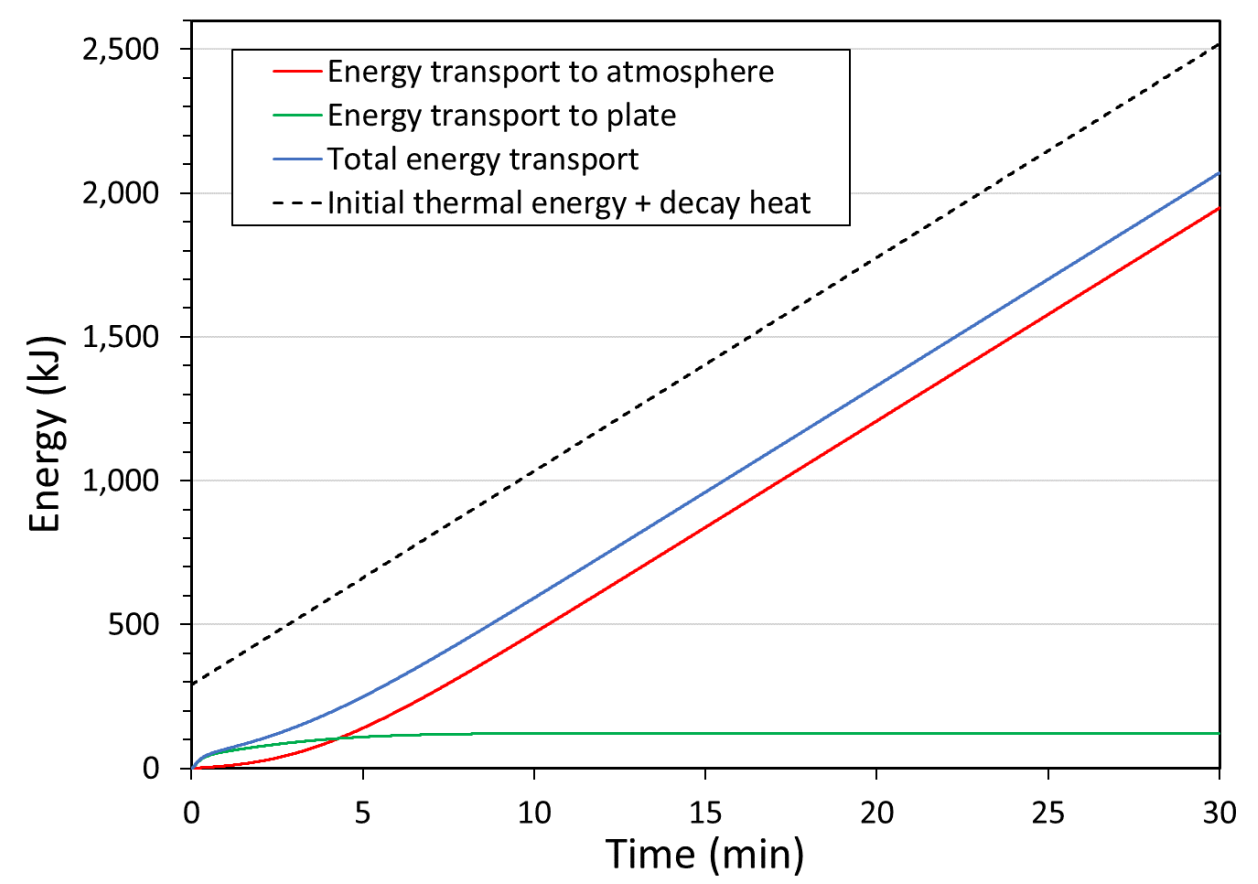

Figure 11: Integrated energy transfer up (to atmosphere) and down (to $1 / 16$ in. thick stainless steel substrate) predicted by MELTSPREAD for the base case pour scenario with $25 \mathrm{MW} \mathrm{m}^{-3}$ of decay heat included.

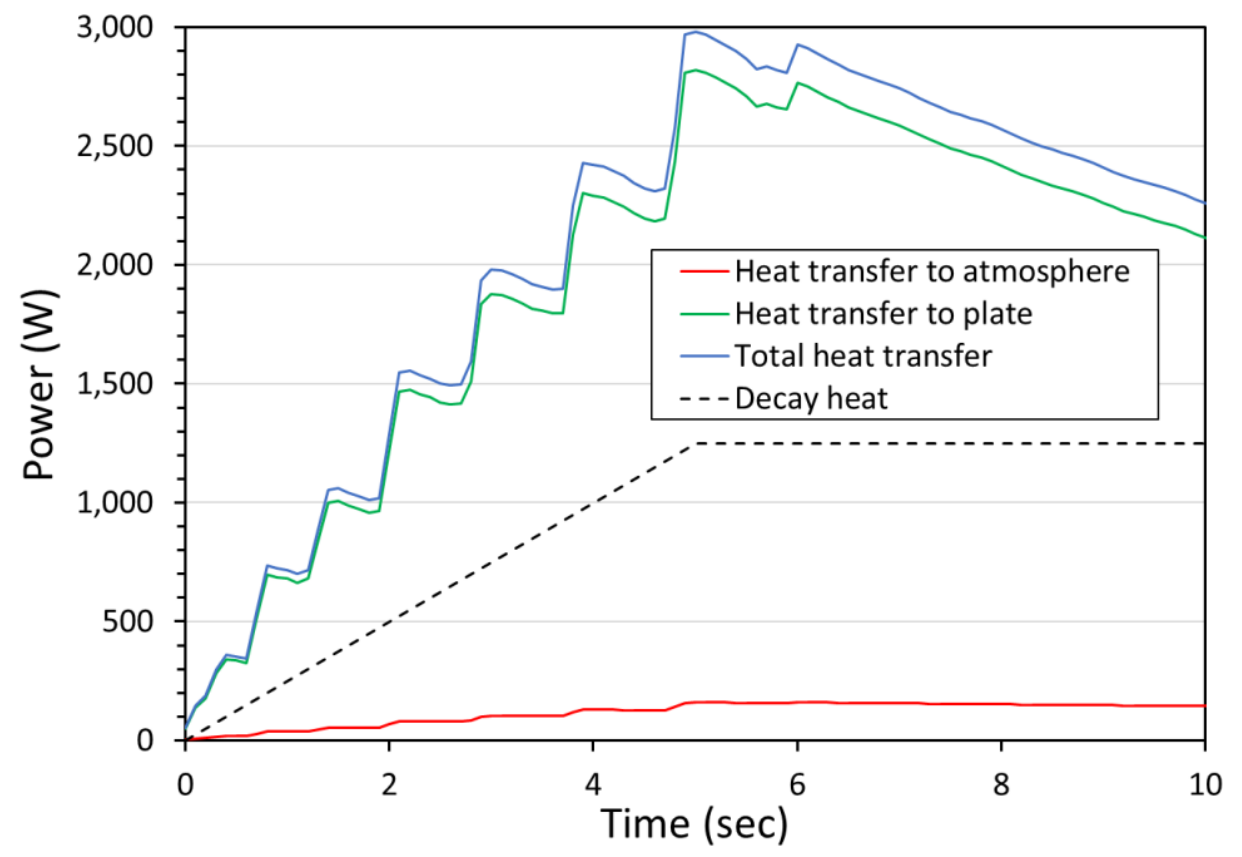

Figure 12: Integrated heat transfer rate up (to atmosphere) and down (to $1 / 16$ in. thick stainless steel substrate) predicted by MELTSPREAD for the first 10 seconds of the base case pour scenario with $25 \mathrm{MW} \mathrm{m}^{-3}$ of decay heat included. The amount of decay heat in the spreading salt is shown by the dashed line. 


\subsection{Uncertainty analysis}

The thermophysical properties and initial conditions that had no effect on the spreading results, as determined by MELTSPREAD, for the ranges of values provided in Table 4 were radiative emissivity, heat of fusion, heat capacity, thermal conductivity, and the initial salt temperature. These properties govern the heat transfer efficiency from the melt to its surroundings. Varying these property values by $\pm 25 \%$ had no effect on spreading because the heat transfer from the salt under the base case conditions was already highly inefficient due to the low thermal conductivity, high heat capacity, and high heat of fusion of FLiNaK.

For a small salt spill on an insulated stainless steel substrate (which is the base case scenario), knowing the heat capacity, heat of fusion, and thermal conductivity within $25 \%$ is likely sufficient to be able to predict the spreading behavior. In addition, changing the radiative emissivity from 1 to 0.9 does not affect spreading behavior because the spreading has already stopped by the time that radiative heat transfer becomes the dominant heat sink. Varying the initial salt temperature from $500{ }^{\circ} \mathrm{C}$ to $800^{\circ} \mathrm{C}$ also does not affect spreading behavior because the cooling duration required to reach the salt freezing temperature is much longer than the time required for the melt to spread to the surface tension-limited spreading area (i.e., 6 seconds).

Varying viscosity and density $\pm 25 \%$ from the base case values had a slight effect on the spreading results and the results are provided in Figure 13 and Figure 14, respectively. A molten salt viscosity that is $25 \%$ greater than the base case value will lead to a slightly smaller spreading area due to the small effect that viscosity has on dampening the effect of inertia on spreading area. One reason why changing the salt density influences spreading is because it relates the salt mass and salt volume. MELTSPREAD requires using total pour mass as input as opposed to volume, so for a constant pour mass, varying the density by $\pm 25 \%$ varies the pour volume by $\pm 25 \%$. The pour volume will determine the maximum spreading area when spreading is limited by surface tension, as it is for the base case scenario.

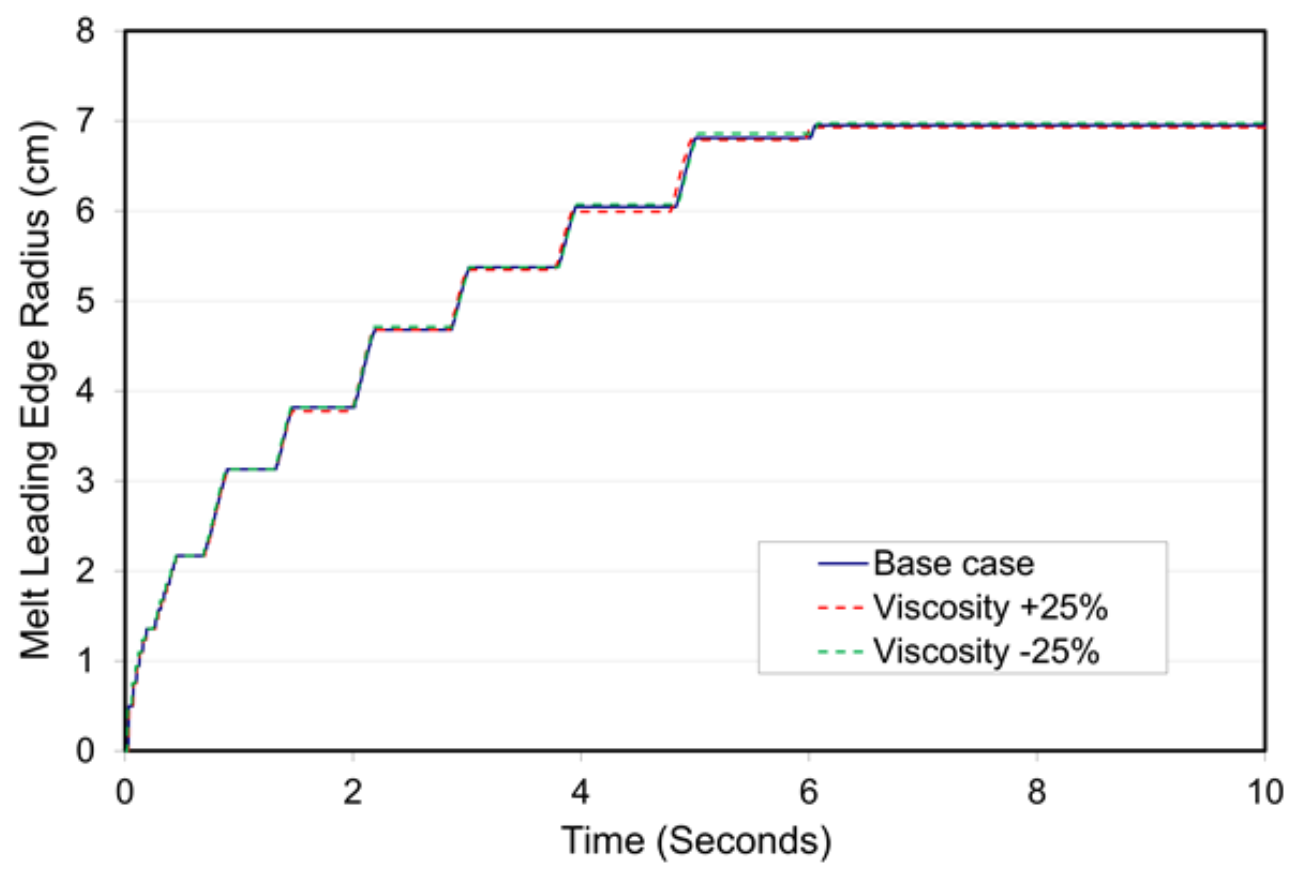

Figure 13: The effect of varying viscosity $\pm 25 \%$ from the base case value on the spreading result. 


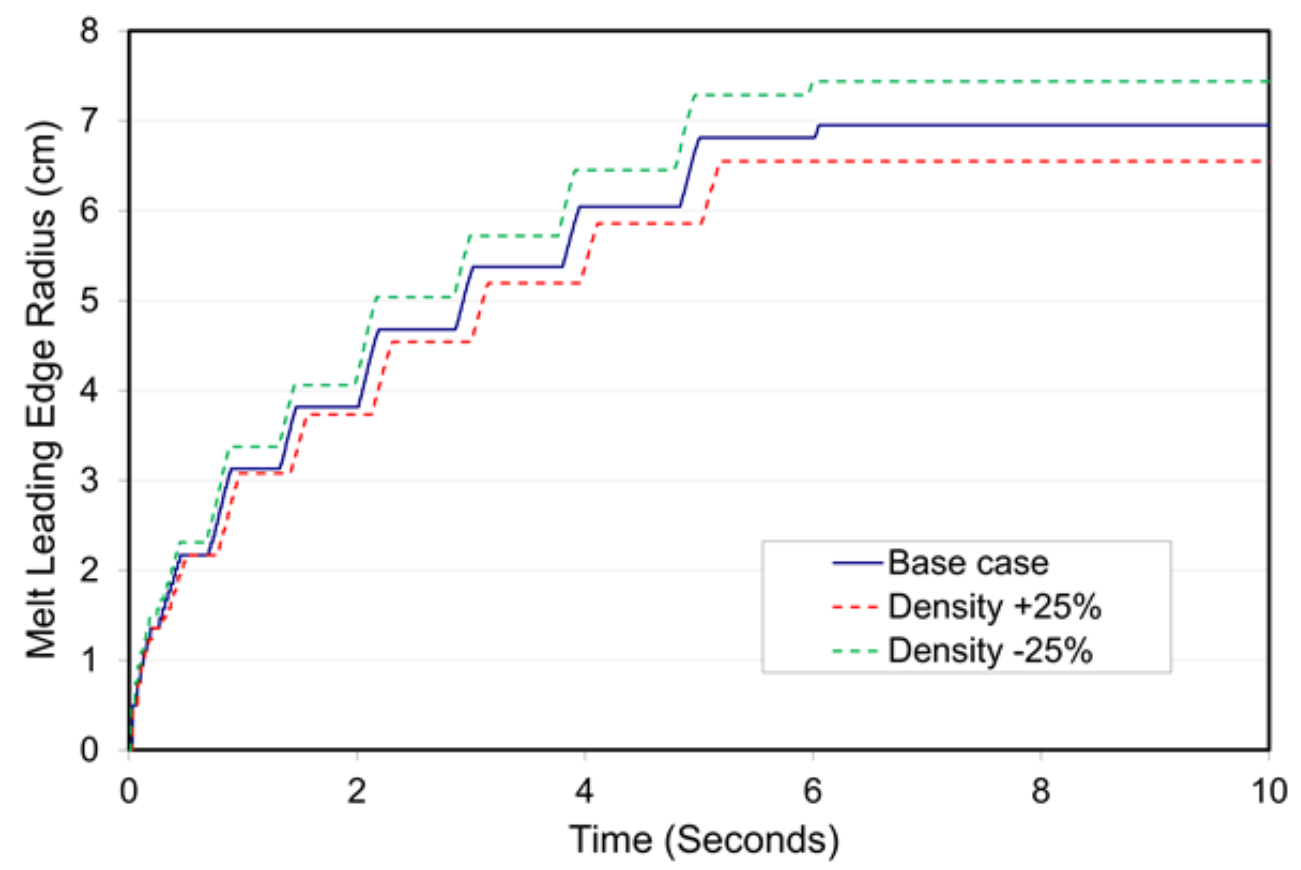

Figure 14: The effect of varying density $\pm 25 \%$ from the base case value on the spreading result.

Varying the mass poured and the pour rate $\pm 50 \%$ from the base case values had a significant effect on the spreading behavior and the results are provided in Figure 15 and Figure 16, respectively.

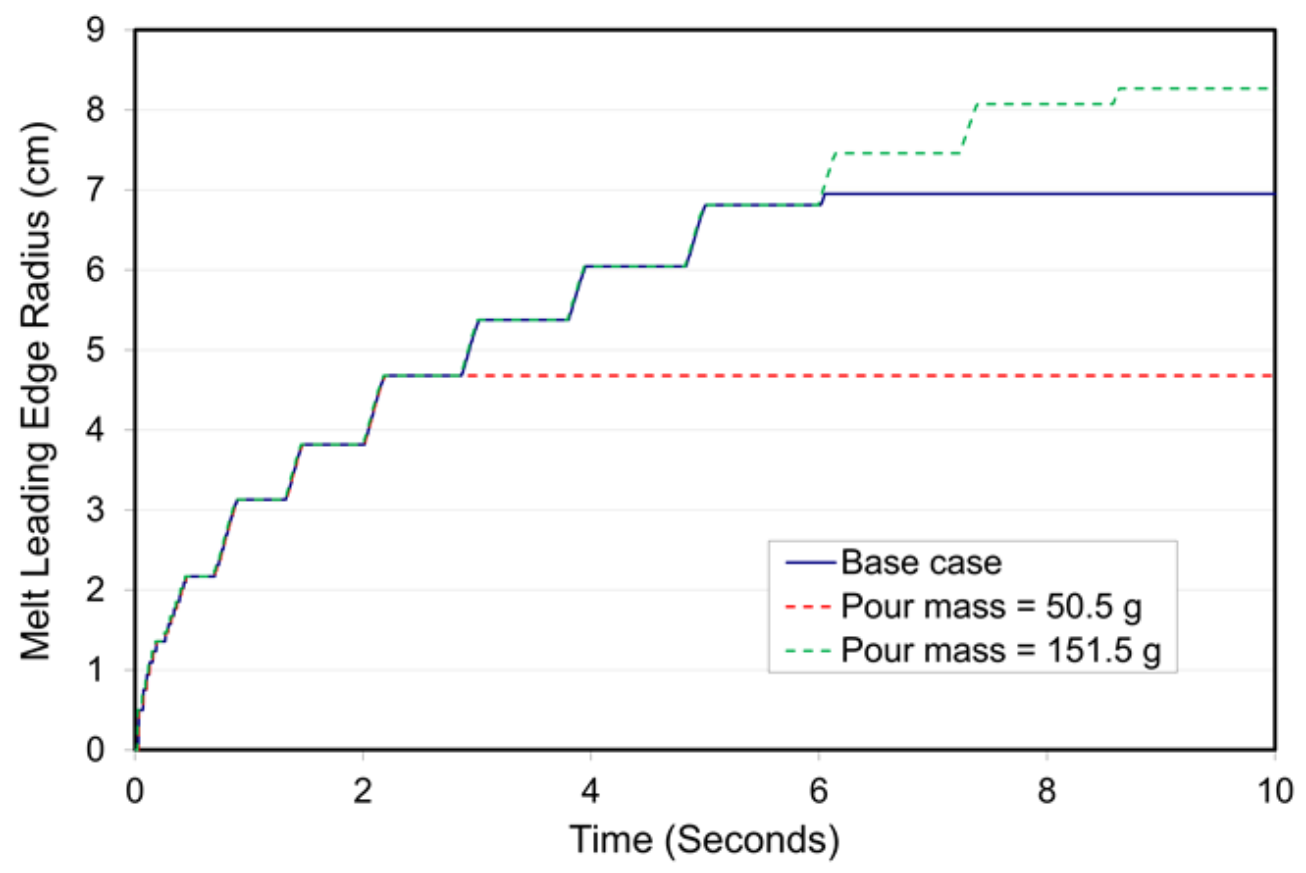

Figure 15: The effect of varying the pour mass $\pm 50 \%$ from the base case value on the spreading result. 


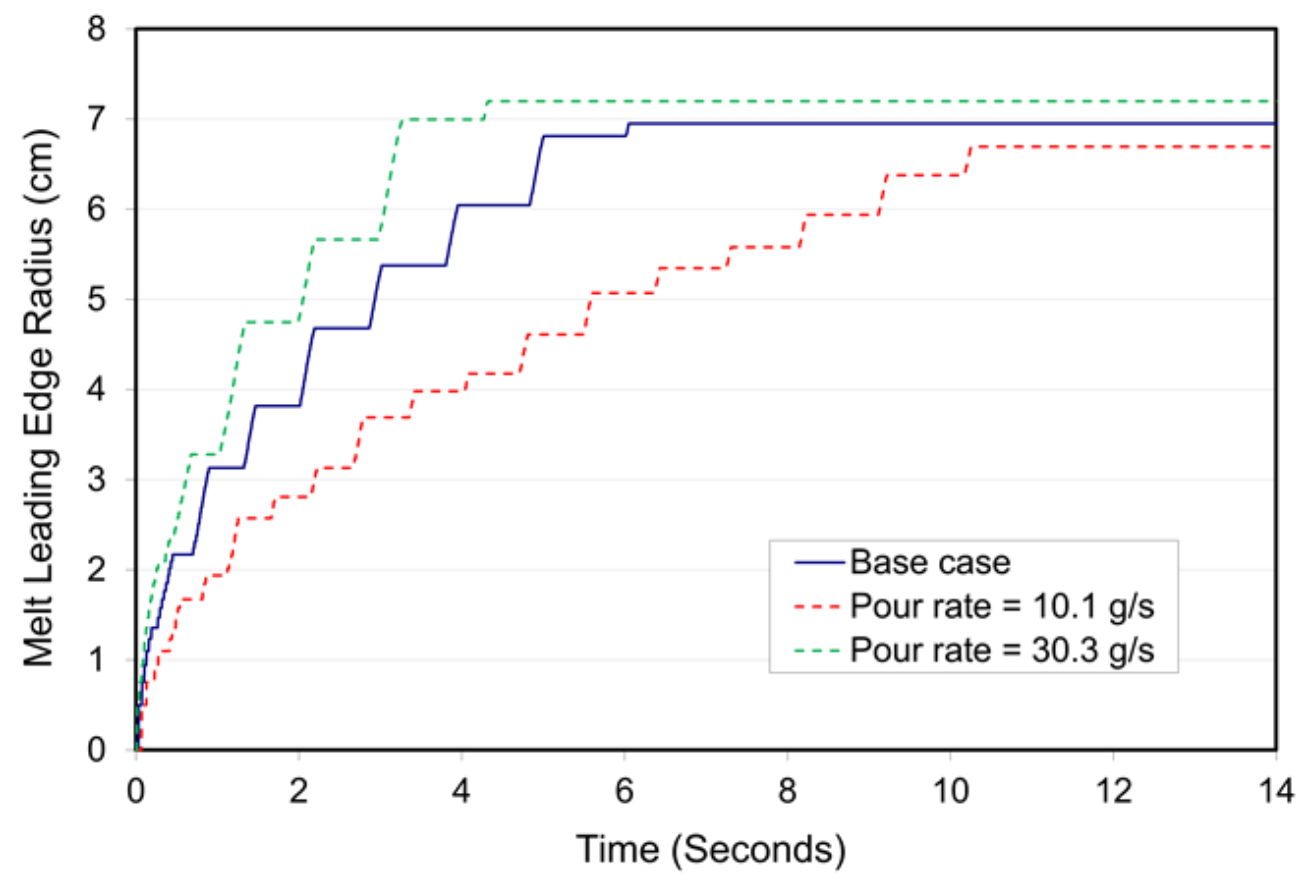

Figure 16: The effect of varying the pour rate $\pm 50 \%$ from the base case value on the spreading result.

Varying the total mass poured had no effect on the velocity of the leading edge but did influence the total extent of spreading (Figure 15), which is expected when spreading is limited by hydrodynamic effects. A $50 \%$ decrease in the pour rate from the base case resulted in a slower leading edge velocity and a slightly smaller spreading area (Figure 16). A $50 \%$ increase in the pour rate from the base case resulted in a faster leading edge velocity and a slightly larger spreading area (Figure 16).

Varying the surface tension $\pm 25 \%$ from the base case value also influenced the spreading behavior of the molten salt (Figure 17). Because the spreading behavior for the base case scenario is limited by surface tension, increasing the surface tension increases the minimum spreading thickness and decreases the spreading area. Likewise, decreasing the surface tension decreases the minimum spreading thickness and increases the spreading area. Salt spreading was also modeled for the base case scenario with a salt surface tension near zero to simulate the salt wetting the stainless steel substrate. It is clear from Figure 17 that when the salt wets the substrate (i.e., when the surface tension 0), the spreading behavior is entirely different from the base case behavior. Specifically, there is no stepping feature in the curve for leading edge as a function of time, which indicates that leading edge effects are negligible when salt wets the substrate surface. In addition, the total spreading area is greater when surface tension is approximately zero because this leads to a lower minimum spreading thickness. 


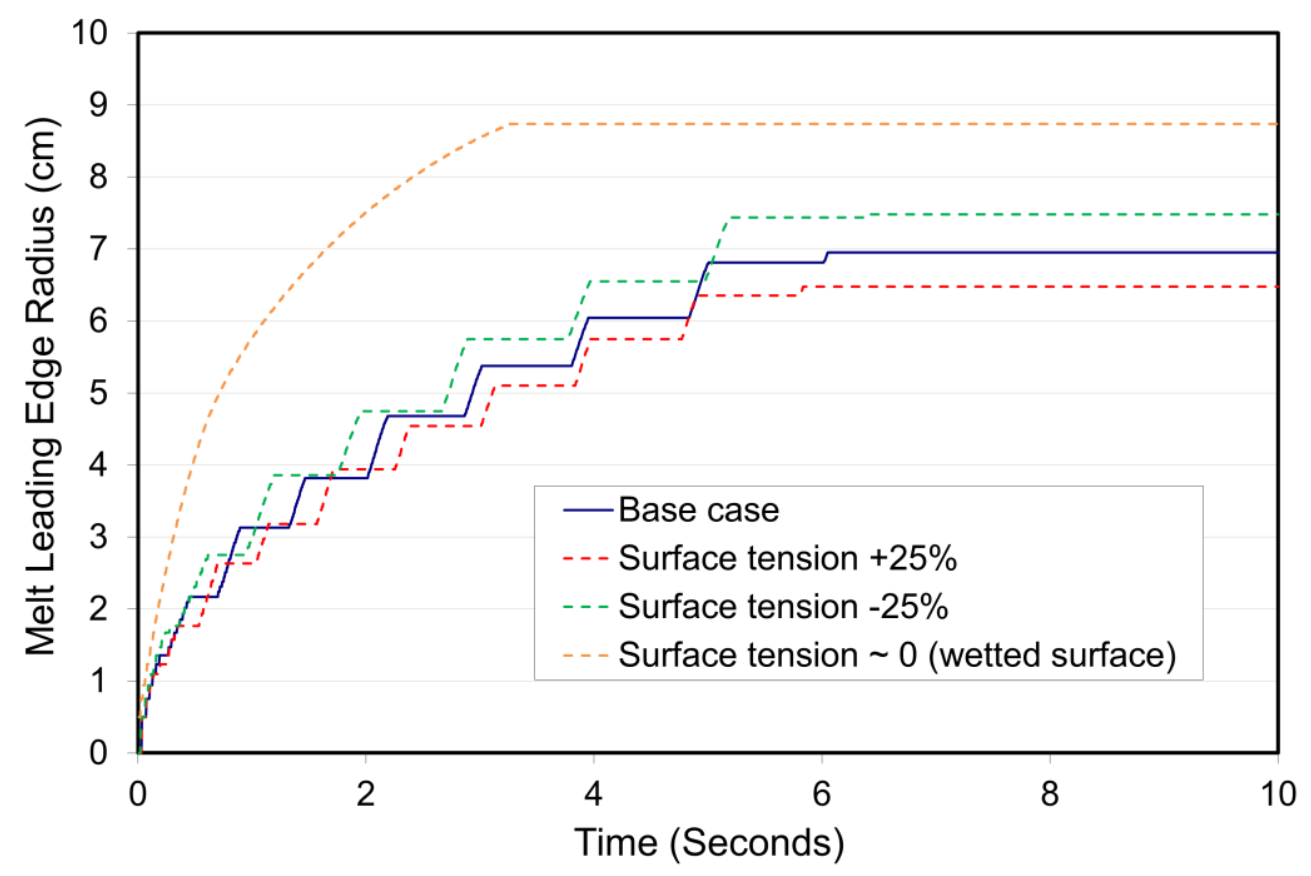

Figure 17: The effect of varying the surface tension $\pm 25 \%$ from the base case value on the spreading result. Spreading results for a wetted surface (surface tension $\sim 0$ ) are also provided.

\section{Conclusions}

MELTSPREAD was updated to model the radial spreading and heat transfer of molten FLiNaK on a flat stainless steel substrate. In the model, the substrate was assumed to be insulated on the underside and natural convective cooling was not included, so heat transfer by conduction to the substrate and radiation to the atmosphere were the only pathways for heat loss from the molten salt. The spreading was limited by the balance between the molten salt surface tension and gravity for the small salt volume $(50 \mathrm{~mL})$, pour conditions, and assumed mechanisms of heat transfer in the model. Spreading was complete approximately six seconds after the salt first touched the stainless steel substrate and the salt was still partially molten 30 minutes after spreading had stopped. Heat transfer from the salt was highly inefficient to due to its low thermal conductivity, high heat capacity, and high heat of fusion. Heat transfer efficiency from the salt increased when the substrate thickness was increased from the base case value (1/16 in.) to $1 / 4$ in., but this had no effect on the overall spreading behavior.

The molten salt pool spread further than the maximum spreading area governed by the balance between surface tension and gravity. This over-spreading is due to inertia and causes the leading edge radius to increase with time in steps. Including $25 \mathrm{MW} \mathrm{m}^{-3}$ of decay heat had a significant effect on the long-term cooling behavior of the molten salt but no effect on the overall spreading behavior. The salt with decay heat gradually heated to approximately $1200^{\circ} \mathrm{C}$ within 10 minutes of the spill, at which temperature radiation heat transfer was able to dissipate the full power of the decay heat to the atmosphere.

Varying the heat of fusion, heat capacity, and thermal conductivity by $\pm 25 \%$ from the base case values; varying the initial salt temperature by $\pm 150^{\circ} \mathrm{C}$; or decreasing the salt emissivity from 1 to 
0.9 had no effect on the spreading results. The spreading of FLiNaK is not limited by salt freezing, so property values related to heat transfer were not required to be precise to understand the bulk spreading behavior for this scenario. The viscosity and density of FLiNaK were found to have a slight effect on the spreading behavior, while the pour mass, pour rate, and surface tension had a more significant effect on spreading. A higher viscosity and a higher density (for a constant pour mass) led to a smaller spreading area. Surface tension influenced the spreading behavior because it determines the minimum spreading thickness for surface tension-limited spreading. When surface tension was set to approximately zero to simulate molten salt wetting the substrate surface, the leading edge effects that were observed in the base case spreading scenario (i.e., the stepping behavior) were eliminated.

The results from these initial model runs provide insight into the spreading behavior of small volumes of molten salt so that they can be compared to benchtop experiments that are currently ongoing at Argonne on molten salt spreading. Future iterations of the model can include more complexity to provide more realistic predictions for molten salt spreading and heat transfer, which include:

- $\quad$ Varying the thermophysical property values with temperature as the salt cools.

- Including natural convective cooling as a heat transfer mechanism.

- $\quad$ Performing spreading calculations on sloped substrates to simulate the sloped catch pans that are incorporated in some MSR designs.

Future modeling effort should also focus on defining a reactor case pour scenario that involves spilling a volume of salt that represents the capacity of MSR reactor vessels and uses a containment geometry characteristic of modern MSR designs. The spreading behavior of large volumes of salt may be entirely different than the spreading behavior of the smaller volumes that were of focus in this document. For example, viscosity is expected to have a larger effect and surface tension is expected to have a smaller effect on spreading behavior for larger salt volumes. Spreading and heat transfer results from the reactor case pour scenario would also provide insight into the design of engineering scale molten salt spill tests to provide experimental data for accident progression model validation. 


\section{References}

Allibert, M., Aufiero, M., Brovchenko, M., Delpech, S., Ghetta, V., Heuer, D., Laureau, A., et al. (2016). "Molten Salt Fast Reactors." In Handbook of Generation IV Nuclear Reactors, 157-88. Elsevier.

Ambrosek, J., Anderson, M., Sridharan, K., and Allen, T. (2009). "Current Status of Knowledge of the Fluoride Salt (FLiNaK) Heat Transfer.” Nuclear Technology 165 (2): 166-73.

Anderson, M., Sridharan, K., Morgan, D., Peterson, P., Calderoni, P., Scheele, R., Casekka, A., et al. (2015). "Heat Transfer Salts for Nuclear Reactor Systems - Chemistry Control, Corrosion Mitigation, and Modeling." DOE/NEUP-10-905.

Brovchenko, M., Heuer, D., Merle-Lucotte, E., Allibert, M., Ghetta, V., Laureau, A., and Rubiolo, P. (2013). "Design-Related Studies for the Preliminary Safety Assessment of the Molten Salt Fast Reactor." Nuclear Science and Engineering 175 (3): 329-39.

Chapdelaine, L. J. (2017). "Experimental and Computational Study of Static Solidification of Molten Fluoride Salts for Reactor Coolant Application." Thesis, University of Wisconsin-Madison.

Chrenkova, M., Daněk, V., Silný, A., Kremenetsky, V., and Polyakov, E. (2003). "Density and Viscosity of the (LiF-NaF-KF) eut $\mathrm{KBD}_{4}-\mathrm{B}_{2} \mathrm{O}_{3}$ Melts." Journal of Molecular Liquids 102 (1-3): 213-26.

Ebert, W. L., and Rose, M. A. (2021). Data Quality of Salt Property Measurements. Argonne National Laboratory report. ANL/CFCT-21/18.

Farmer, M. T. (2009). "Melt Spreading Code Assessment, Modifications, and Applications to the EPR Core Catcher Design." Argonne National Laboratory report. ANL-09/10.

Farmer, M. T. (2017). "The MELTSPREAD Code for Modeling of Ex-Vessel Core Debris Spreading Behavior." Code Manual - Version3-beta. Argonne National Laboratory report. ANL/NE-17/20.

Farmer, M. T., Robb, K. R., and Francis, M. W. (2016). "Fukushima Daiichi Unit 1 Ex-Vessel Prediction: Core Melt Spreading." Nuclear Technology 196 (3): 446-60.

Jerden, J. (2019). "Molten Salt Thermophysical Properties Database Development: 2019 Update." Argonne National Laboratory report. ANL/CFCT-19/6.

Lichtenstein, T., Rose, M. A., Krueger, J., Wu, E., and Williamson, M. A. (2020). "Thermochemical Property Measurements of FLiNaK and FLiBe in FY 2020." Argonne National Laboratory report. ANL/CFCT-20/37.

Serrano-López, R., Fradera, J., and Cuesta-López, S. (2013). "Molten Salts Database for Energy Applications." Chemical Engineering and Processing: Process Intensification 73: 87-102.

Sohal, M. S., Ebner, M. A., Sabharwall, P., and Sharpe, P. (2013). "Engineering Database of Liquid Salt Thermophysical and Thermochemical Properties." Idaho National Laboratory report. INL/EXT-10-18297.

Thomas, S. and Jackson, J. (2021). "Testing to Evaluate Processes Expected to Occur during MSR 
Salt Spill Accidents." Argonne National Laboratory report. ANL/CFCT-21/22.

Thomas, S. and Jerden, J. (2020). "Mechanistic Source Term Development for Liquid Fueled MSRs - Model Development Update." Argonne National Laboratory report. ANL/CFCT-20/16.

Williams, D. F. (2006). "Additional Physical Property Measurements and Assessment of Salt Compositions Proposed for the Intermediate Heat Transfer Loop." Oak Ridge National Laboratory report. ORNL/GEN4/LTR-06-033.

Yoder, G. L., Heatherly, D., Williams, D., Caja, J., Caja, M., Elkassabgi, Y., Jordan, J., et al. (2014). "Liquid Fluoride Salt Experiment Using a Small Natural Circulation Cell." Oak Ridge National Laboratory report. ORNL/TM-2014/56. 


\section{Appendix A: Estimating spreading area limit due to heat transfer and surface tension}

The actual spreading area of a melt will either be limited by melt freezing (heat transfer) or the balance between the surface tension of the melt and gravity, depending on the time at which the melt freezes. The actual melt spreading area $\left(A_{s}\right)$ is thus defined as:

$$
A_{s}=\operatorname{minimum}\left\{\begin{array}{l}
A_{s, H D} \\
A_{S, H T}
\end{array}\right.
$$

where $A_{S, H D}$ is the hydrodynamic surface tension limit on the spreading area and $A_{s, H T}$ is the heat transfer limit on spreading area.

\section{A.1 Estimating the heat transfer limited spreading area}

This section describes a method to estimate the heat transfer limited spreading area of a melt on a flat substrate. The rate of heat injection during the melt pour $\left(\dot{Q}_{p}\right)$ can be expressed as:

$$
\dot{Q_{p}}=\dot{m}_{p} \Delta \mathrm{E}_{\mathrm{f}}
$$

where $m_{p}$ is the mass flow rate of the pour and $\Delta \mathrm{E}_{\mathrm{f}}$ is the change in enthalpy from the original state of the poured melt to the freezing temperature.

The total rate of heat transfer from the melt to the surrounding environment can be described as the sum of the heat transfer rates to the upper atmosphere (up) and the underlying substrate (down). Heat loss to the upper atmosphere will be dominated by thermal radiation, while heat loss to the substrate is due to forced convection. The assumption is made here that the melt will spread to the point where the rate of heat injection due to the pour $\left(\dot{Q}_{p}\right)$ is balanced by heat transfer up and down; i.e.,

$$
\dot{Q_{p}}=A_{s, H T}\left(\overline{q_{u p}{ }^{\prime \prime}}+\overline{q_{\text {down }}{ }^{\prime \prime}}\right)
$$

where $A_{s, H T}$ is the heat transfer limited spreading area, $\overline{q_{u p}{ }^{\prime \prime}}$ is the average heat flux up due

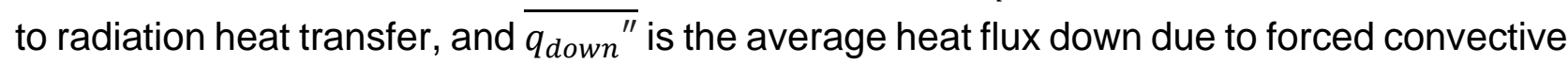
heat transfer. The radiation heat flux from the melt is expressed as:

$$
q_{u p}{ }^{\prime \prime}=\frac{\sigma_{s t}}{\left(1 / \epsilon_{m}+1 / \epsilon_{s t}-1\right)}\left(T_{p}{ }^{4}-T_{s t r u c}{ }^{4}\right)
$$

where $\epsilon_{m}$ is the emissivity of the melt, $\epsilon_{s t}$ is the emissivity of the overlying structure (e.g., the interior walls of containment structure), $\sigma_{s t}$ is the Stefan-Boltzman constant 
$\left(5.67 \times 10^{-8} \mathrm{~W} \mathrm{~m}^{-2} \mathrm{~K}^{-4}\right), T_{p}$ is the initial temperature of the poured melt, and $T_{\text {struc }}$ is the internal temperature of the structure to which heat is radiated.

The average heat flux due to radiation can be written as follows:

$$
\begin{gathered}
\overline{q_{u p}{ }^{\prime \prime}}=\frac{1}{T_{p}-T_{\text {solidus }}} \int_{T_{\text {solidus }}}^{T_{p}} q_{u p}{ }^{\prime \prime}(T) d T \\
=\frac{\sigma_{\text {st }}}{\left(1 / \epsilon_{m}+1 / \epsilon_{\text {st }}-1\right)}\left(\frac{1}{T_{p}-T_{\text {solidus }}}\right)\left[\frac{T_{p}{ }^{5}}{5}-T_{\text {struc }}^{4} T_{p}-\frac{T_{\text {solidus }}^{5}}{5}+T_{\text {struc }}^{4} T_{\text {solidus }}\right]
\end{gathered}
$$

The heat flux down to the substrate is approximated with the following equation:

$$
q_{\text {down }} "=h_{\text {down }}\left(T_{p}-T_{\text {solidus }}\right)
$$

where $h_{\text {down }}$ is the convective heat transfer coefficient and $T_{\text {solidus }}$ is the solidus temperature of the melt.

Equation 6 assumes convective heat transfer is limited by crust formation at the lower surface. Another assumption is the convective heat transfer coefficient is given by the Dittus-Boelter correlation:

$$
h_{\text {down }}=\left\{\begin{array}{c}
\frac{7.6 k}{D_{h}}, R e<2300 \\
0.023 R e^{0.8} \operatorname{Pr}^{0.4} \frac{k}{D_{h}}, R e>2300
\end{array}\right.
$$

Where $R e$ is the Reynolds number, $D_{h}$ is the hydraulic diameter, $k$ is the melt thermal conductivity, and $\mathrm{Pr}$ is the melt Prandtl number. The hydraulic diameter can be approximated as 4 times the vertical spreading area $\left(A_{\text {vert }}\right)$ divided by the melt wetted perimeter $\left(P_{\text {wet }}\right)$ :

$$
D_{h}=\frac{A_{\text {vert }}}{P_{\text {wet }}}=\frac{4 L H}{L}=4 H
$$

where $L$ is the spreading length and $H$ is the thickness of the melt.

As a first approximation, assume that heat transfer is limited by conduction ( $R e$ is below 2300 in Equation 7). Therefore, the convective heat transfer coefficient can be simplified as follows:

$$
h_{\text {down }}=\frac{7.6 k}{D_{h}}=\frac{7.6 k}{4 H}=\frac{1.9 k}{H}
$$


The average heat flux down from the spreading melt can be calculated as shown:

$$
\begin{gathered}
\overline{q_{\text {down }} "}=\frac{h_{\text {down }}}{T_{p}-T_{\text {solidus }}} \int_{T_{\text {solidus }}}^{T_{p}}\left(T-T_{\text {solidus }}\right) d T \\
=\frac{0.85 k}{H}\left(T_{p}-T_{\text {solidus }}\right)
\end{gathered}
$$

It is important to note that the melt height $(H)$ is a function of the spreading area, which is not known. Assuming an even salt thickness throughout the spreading melt, the melt height can be written in terms of the melt mass $(m)$, density $(\rho)$, and spread area $\left(A_{s, H T}\right)$ :

$$
H=\frac{m}{\rho A_{s, H T}}
$$

Reorganizing Equation 10 yields:

$$
\overline{q_{\text {down }}{ }^{\prime \prime}}=\frac{0.85 k \rho A_{s, H T}}{m}\left(T_{p}-\text { Tsolidus }\right)
$$

The heat transfer rate from the melt to the substrate is then calculated as follows:

$$
\dot{Q}_{\text {down }}=\frac{0.85 k \rho A_{s, H T}^{2}}{m}\left(T_{p}-\text { Tsolidus }\right)
$$

For simplification, a constant $\left(C_{\text {down }}\right)$ is defined:

$$
C_{\text {down }}=\frac{0.85 k \rho}{m}\left(T_{p}-T \text { solidus }\right)
$$

The heat transfer balance (Equation 3) then becomes:

$$
\dot{Q}_{p}=C_{\text {down }} A_{s, H T}^{2}+\overline{q_{u p}} A_{s, H T}
$$

Equation 15 is then reorganized to solve for the spreading area: 


$$
A_{s, H T}=\frac{1}{2} \sqrt{\left(\frac{q_{\text {up }}{ }^{\prime \prime}}{C_{\text {down }}}\right)^{2}+\frac{4 \dot{Q}_{p}}{C_{\text {down }}}}-\frac{\overline{q_{u p}{ }^{\prime \prime}}}{2 C_{\text {down }}}
$$

\section{A.2 Estimating the surface tension limited spreading area}

This section describes a method to estimate the surface tension limited spreading area of a melt on a flat substrate. The hydrodynamic surface tension limit on the spreading area $\left(A_{s, H D}\right)$ is provided by Equation 17:

$$
A_{S, H D}=\frac{(m / \rho)}{H_{S T}}
$$

where $H_{S T}$ is the surface tension limited spreading melt thickness, $m$ is the mass of the melt, and $\rho$ is the density of the melt. $H_{S T}$ is determined by setting the gravity head at the leading edge $\left(\rho H_{S T} g\right)$ equal to the effective surface tension pressure $\left(2 \sigma / H_{S T}\right)$, which yields:

$$
H_{S T}=\sqrt{\frac{2 \sigma}{\rho g}}
$$

where $g$ is the acceleration due to gravity $\left(9.81 \mathrm{~m} \mathrm{~s}^{-2}\right)$ and $\sigma$ is the surface tension of the melt. 


\section{Argonne}

\section{Chemical and Fuel Cycle Technologies Division}

Argonne National Laboratory

9700 South Cass Avenue, Bldg. 205

Argonne, IL 60439

www.anl.gov 